\title{
Interfacial Behavior of Ionophoric Systems: Molecular Dynamics Studies on 18-Crown-6 and Its Complexes at the Water-Chloroform Interface
}

\author{
L. Troxler and G. WIPFF ${ }^{\dagger}$
}

Laboratoire MSM, UMR 7551 CNRS, Institut de Chimie, 4, rue B. Pascal, 67000 Strasbourg, France

\begin{abstract}
We report a series of molecular dynamics simulations on 18-crown-6 (18C6) uncomplexed, and on its $\mathrm{K}^{+} \mathrm{Pic}^{-}$complexes, at the water-chloroform interface, using an explicit representation of the solvents. The (18C6) $)_{10}$ aggregate, initially at the interface, displays after $1 \mathrm{~ns}$ a complex equilibrium between molecules adsorbed at the interface, and others which have diffused to the organic phase. The $\left(18 \mathrm{C} 6 \cdot \mathrm{K}^{+} \mathrm{Pic}^{-}\right)_{6}$ inclusive complexes, initially at the interface, also display after $1 \mathrm{~ns}$, an equilibrium between $18 \mathrm{C} 6$ molecules, $18 \mathrm{C} 6 \cdot \mathrm{K}^{+}$complexes and the $\mathrm{Pic}^{-}$counterions adsorbed at the interface, while some decomplexed $\mathrm{K}^{+}$cations are captured by water. The spontaneous migration of a $18 \mathrm{C} 6 \cdot \mathrm{K}^{+}$complex to the organic phase is also observed, facilitated by specific water molecules and the Pic ${ }^{-}$counterions. Comparison with simulations on the $\left(18 \mathrm{C} 6 \cdot \mathrm{K}^{+} \mathrm{Pic}^{-}\right)_{1}$ and $\left(18 \mathrm{C} 6 \cdot \mathrm{Sr}^{2+} 2 \mathrm{Pic}^{-}\right)_{1}$ complexes highlights the effect of concentration and of the cationic charge on the interfacial behavior. We finally describe a "computer extraction experiment", which starts with 18C6 molecules in the organic phase and $\mathrm{K}^{+} \mathrm{Pic}^{-}$ion pairs in water. The results are discussed in relation with experimental data. We emphasize the surfactant-like behavior of free and complexed extractant molecules, the preorganization of ionophores induced by the interface, and the role of counterions. Surface active anions attract the cations at the interface and facilitate their capture by the adsorbed ionophores. Synergistic effects should result from the adsorption of co-extractant molecules or/and of counterions at the interface.
\end{abstract}

Keywords Liquid-liquid extraction, interface, ionophores, molecular recognition, surfactants, hydrometallurgy, adsorption, counterion effect, synergy, solvation, molecular dynamics

Since the discovery of the remarkable ion binding properties of crown ethers ${ }^{1}$ and cryptands ${ }^{2}$, impressive achievements have been accomplished in the design and study of macro(poly)cyclic hosts able to selectively bind or extract cations in solutions. ${ }^{2,3}$ Ion separation by liquid-liquid extraction or transport represents indeed a major theme of supramolecular chemistry, as well as of ion-coordination chemistry. ${ }^{4-6}$ In these processes, a key feature concerns the assisted ion transfer through the interface which separates the source and receiving phases. The question on what happens at the liquid-liquid interface concerns not only ion separation, but also electrochemistry ${ }^{7}$, physical chemistry of interfaces ${ }^{8}$, chemical reactivity (e.g. phase transfer catalysis $\left.{ }^{9}\right)$, etc.

The interface of extraction systems is usually studied by measuring the interfacial tension, viscosity and potential. ${ }^{8}$ Spectroscopic methods are also beginning to emerge, that provide structural insights into molecules adsorbed at interface ${ }^{10}$ but data related to ion extraction systems are relatively scarce. ${ }^{11}$ Computer simulations constitute a promising approach to study the structure of interfaces between neat liquids ${ }^{12,13}$, or in the presence of neutral solutes ${ }^{14}$, or of ions. ${ }^{15,16}$

The purpose of this paper is to investigate the interfa-

To whom correspondence should be addressed. cial behavior of 18C6 (18-crown-6), in relation with its ionophoric properties. This is part of a series of simulations on extractant molecules at the ITIES (interface between two non miscible solvents). In previous publications we considered monomers of calixarenes, cryptand, in various conformations ${ }^{17}$, and of their cation complexes ${ }^{17-19}$ at the water chloroform interface. Other extractant molecules like $\mathrm{CMPO}^{20}, \mathrm{TBP}^{21}$, phosphoryl containing podants molecules ${ }^{19}$, valinomycin ${ }^{22}$ were also simulated. One important result was the high affinity of these species for the interface. Although they are more soluble in chloroform than in water, they were found to adsorb to the interface, instead of migrating to chloroform. They therefore behave as surfactants. The question of counterions on interfacial activity was also studied by comparing the hydrophilic $\mathrm{Cl}^{-}$with the amphiphilic Pic ${ }^{-}$counterion, widely used in extraction experiments, and the free energy profiles for unassisted/ assisted ion transfer were calculated. ${ }^{22}$ In those studies, however, one single solute molecule was considered, and it was stressed that the interfacial behavior might depend on the concentration of the salts and ligands. The purpose of this study is to investigate more complex systems, starting with aggregates of the free or complexed ionophore. Compared to the previous studies, the time scales are larger (1 ns for each system). 
From the methodological point of view, we also explore the questions of long range electrostatic forces on the interfacial behavior, by performing the simulations using the Ewald summation method.

More specifically, the following systems have been simulated: the (18C6) 10 aggregate of uncomplexed hosts, the $\left(18 \mathrm{C} 6 \cdot \mathrm{K}^{+} \mathrm{Pic}^{-}\right)_{6},\left(18 \mathrm{C} 6 \cdot \mathrm{K}^{+} \mathrm{Pic}^{-}\right)_{1}$ and $(18 \mathrm{C} 6 \cdot$ $\left.\mathrm{Sr}^{2+} 2 \mathrm{Pic}^{-}\right)_{1}$ complexes, simulated starting at the interface, equally shared between the two solvent phases. Finally, we performed two simulations of an "ion extraction experiment", starting with six 18C6 molecules in the bulk organic phase, next to an aqueous solution of six $\mathrm{K}^{+} \mathrm{Pic}^{-}$ions. The choice of $\mathrm{K}^{+}$as potential guest comes from the binding specificity of $18 \mathrm{C} 6$ and its derivatives for this ion in most solvents. , $6,23^{1,23}$

The 18C6 molecule, which is one of the cornerstones of supramolecular chemistry ${ }^{1,3,5}$, has been the target of most of the computer simulation methods. After the first molecular mechanics studies of 18C6 free and complexed in the gas phase ${ }^{24}$, its conformational state has been investigated by MD (molecular dynamics) or Monte Carlo simulations, in the gas phase ${ }^{25,26}$ and in polar solutions like water ${ }^{27,28}$, acetonitrile ${ }^{29}$, or the pure liquid phase ${ }^{30}$ as well as in apolar solvents. ${ }^{31}$ The question of ion binding selectivity in solution has also been extensively explored by MD techniques. ${ }^{29,32}$ Important insights into the ion binding features are beginning to emerge from QM simulations on the complexes in the gas phase. ${ }^{33}$ However, to our knowledge, no theoretical investigation of its interfacial behavior has been reported so far.

\section{Methods}

\section{Representation of the system}

We used the modified AMBER4.1 software $^{34}$ with the following representation of the potential energy:

$$
\begin{aligned}
E_{\mathrm{T}}= & \sum_{\text {bonds }} K_{\mathrm{r}}\left(r-r_{\mathrm{eq}}\right)^{2}+\sum_{\text {angles }} K_{\theta}\left(\theta-\theta_{\mathrm{eq}}\right)^{2} \\
& +\sum_{\text {dihedrals }} \sum_{\eta} \frac{V_{\eta}}{2}(1+\cos n \Phi)+\sum_{j=1}^{\text {atoms atoms }} \sum_{i>j}\left[\varepsilon_{i j}\left(\frac{R_{i j}{ }^{*}}{R_{i j}}\right)^{12}\right. \\
& \left.-2 \varepsilon_{i j}\left(\frac{R_{i j}{ }^{*}}{R_{i j}}\right)^{6}+\frac{q_{i} q_{j}}{R_{i j}}\right]
\end{aligned}
$$

The bonds and bond angles are treated as harmonic springs and a torsional term is associated to the dihedral angles. The interaction between atoms separated by at least three bonds are described within a pairwise additive scheme by a 1-6-12 potential. Parameters for the solutes were taken from the AMBER force field ${ }^{35}$ and our previous studies on $18 \mathrm{C} 6$. The atomic charges on $18 \mathrm{C} 6\left(q_{\mathrm{O}}=-0.404, q_{\mathrm{C}}=0.244, q_{\mathrm{H}}=-0.021\right)$ from ref. 26 were used without special scaling factor for $1 \cdots 4$ interactions. The $\mathrm{Pic}^{-}$anion is described in ref. 36. For the solvents, we used the TIP3P model for water ${ }^{37}$ and the OPLS model for chloroform ${ }^{38}$, where $\mathrm{CH}$ is represented in the united atom approximation. All $\mathrm{C}-\mathrm{H}$, $\mathrm{O}-\mathrm{H}, \mathrm{H} \cdots \mathrm{H}, \mathrm{C}-\mathrm{Cl}$ and $\mathrm{Cl} \cdots \mathrm{Cl}$ "bonds" were constrained with SHAKE, using a time step of $1 \mathrm{fs}$. In all simulations, a residue based cut-off of $12 \AA$ was used for the non-bonded interactions, where each $18 \mathrm{C} 6$ and each ion is topologically defined as a single residue.

Calculations on charged systems (with $6 \mathrm{~K}^{+}$and $6 \mathrm{Pic}^{-}$ ions) were performed first with the "standard procedure" (where non-bonded interactions beyond the cutoff distance are neglected), and then using the Ewald summation method as implemented in AMBER 4.1. Strictly speaking this method, inspired from calculation of electrostatic interactions in three dimensional periodic systems like crystal (see ref. 39) does not apply to interfaces. However, when compared to standard calculations, it gives indirectly insights into the effect of long range electrostatic interactions on the behavior of the system.

The solvent biphasic system was built from two adjacent "rectangular" boxes of pure chloroform and water (Fig. 1). The number of solvent molecules and the sizes of the cells are presented in Table 1. As they are relatively constant for all systems, the solutions of $\left(18 \mathrm{C} 6 \cdot \mathrm{K}^{+} \cdot \mathrm{Pic}^{-}\right)_{6}$ are about six times more concentrated than those of $\left(18 \mathrm{C} 6 \cdot \mathrm{K}^{+} \mathrm{Pic}^{-}\right)_{1}$ or of $\left(18 \mathrm{C} 6 \cdot \mathrm{Sr}^{2+} \cdot 2 \mathrm{Pic}^{-}\right)_{1}$ (about 0.12 and $0.02 \mathrm{~mol} / \mathrm{l}$, respectively)

The MD simulations were performed in the $(\mathrm{N}, \mathrm{V}, \mathrm{T})$ ensemble using a density rescaling procedure of the coordinates before minimization in order to start with the experimental density of chloroform $\left(1.49 \mathrm{~g} \mathrm{~cm}^{-3}\right) .{ }^{40}$ MD started with random velocities at $300 \mathrm{~K}$, and the temperature was controlled by coupling to a thermal bath ${ }^{41}$ with a relaxation time of 0.2 ps. For the "standard calculations" (no-Ewald), periodic boundary conditions were applied along the $x, y$ directions only, and a restraining force $F_{\text {restraint }}$ of $15 \times\left(z-z_{\text {solv }}\right)^{2} \mathrm{kcal} / \mathrm{mol} \AA$ was added at the $z$ edges to prevent evaporation of molecules outside the box $\left(z_{\text {solv }}=z_{\text {-chl }}\right.$ or $z_{\text {-wat, }}$, see Fig. 1$)$. In the calculations performed with the Ewald summation, the periodicity was applied in the three directions. Thus, the solvents are represented as slices, whose $z$ edges correspond to either another liquid/liquid inter-

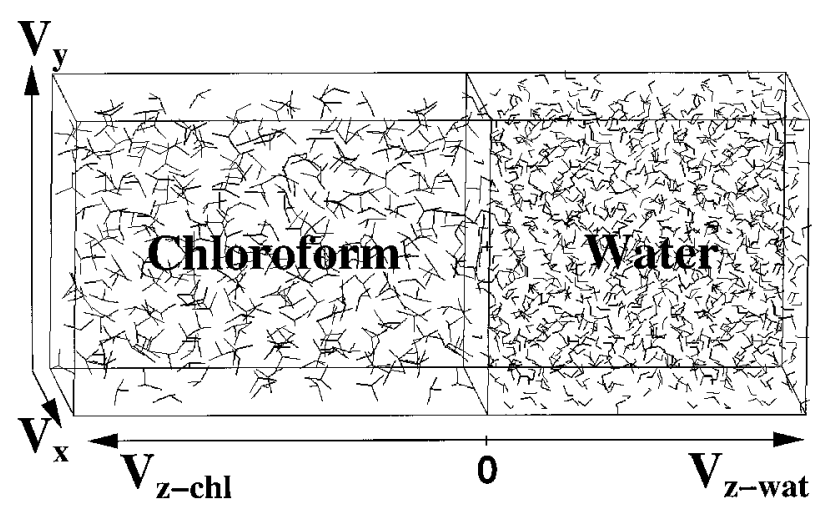

Fig. 1 Schematic representation of the simulation box. 
Table 1 Conditions of simulation: number of solvent molecules, box size $\left(\AA^{3}\right)$, and concentration with respect to the two liquid phases (mol/l)

\begin{tabular}{lcccc}
\hline \multicolumn{1}{c}{ Solute } & nb water & nb chloro & Box size & Concentration \\
\hline$(18 \mathrm{C} 6)_{10}$ & 808 & 251 & $33 \times 33 \times(27+44)$ & 0.215 \\
$\left(18 \mathrm{C} 6 \cdot \mathrm{K}^{+} \mathrm{Pic}^{-}\right)_{1}$ & 1013 & 305 & $31 \times 31 \times(32+42)$ & 0.023 \\
$\left(18 \mathrm{C} 6 \cdot \mathrm{K}^{+} \mathrm{Pic}^{-}\right)_{6}$ & 1088 & 325 & $33 \times 33 \times(33+42)$ & 0.122 \\
$6(18 \mathrm{C} 6)_{\mathrm{chl}} / 6\left(\mathrm{~K}^{+} \mathrm{Pic}^{-}\right)_{\text {wat }}$ & 1220 & 314 & $34 \times 34 \times(35+42)$ & 0.112 \\
$\left(18 \mathrm{C} 6 \cdot \mathrm{Sr}^{2+} 2 \mathrm{Pic}^{-}\right)_{1}$ & 1477 & 445 & $38 \times 38 \times(32+42)$ & 0.016 \\
\hline
\end{tabular}

a. See Fig. 1 for definition of the $V_{\mathrm{x}} \times V_{\mathrm{y}} \times\left(V_{\mathrm{z} \text {-wat }}+V_{\mathrm{z} \text {-chlor }}\right)$ parameters.

face (calculations with Ewald), or to a liquid/vacuum interface (calculations without Ewald).

\section{Analysis of results}

The trajectories saved every $0.2 \mathrm{ps}$ were analyzed with our $\mathrm{MDS}^{42}$ and DRAW ${ }^{43}$ softwares. The $z$ position of the interface was defined as the intersection of the density curves of the two liquids, recalculated at every set. The position of the different moieties of the solute (18C6, the $\mathrm{Pic}^{-}$counterion, $\mathrm{K}^{+}$and $\mathrm{Cl}^{-}$ions) with respect to the interface was defined by the $z$ distance between their center of mass and the interface. For a purpose of simplification, some residues which displayed similar behavior were grouped together for averaging. We also calculated the normalized density curves of these species, as a function of the $z$ coordinate, in the first and last windows of the simulations. As they are difficult to read, they are not presented here, but can be obtained from the authors on request.

The interaction energies between the different moieties of the solute (cation, anion, ligand) and each solvent have been recalculated from the trajectories. Average values are reported in Tables 2 and 3 . Averages at the beginning/the end of the simulations give insight into some of the "driving forces" of the dynamics. Averages are also reported for those of the species which, at the end of the simulation, sit "at the interface" (within $4 \AA$ ), and for those which sit "in the bulk" phases. For consistency, the analysis of Ewald and no-Ewald trajectories have been performed within the $12 \AA$ cut-off distance only, without further correction.

\section{Results}

This simulated systems display some complexity and dynamics features, which can hardly be accounted for by a few static pictures, nor to a few time dependent selected parameters. Computer graphics stereo and color coded views are necessary to follow the trajectories of the different moieties of the solute and their solvation.

Generally, the results of each system depend on the way the electrostatic interactions are calculated. The motions and structural reorganizations that take place with Ewald are reduced, compared to those obtained in the same conditions without Ewald. In the following, we first describe the (18C6) 10 aggregate of the uncomplexed crown. This is followed by several simulations on its $\mathrm{K}^{+} \mathrm{Pic}^{-}$complexes in different concentrations, and initial conditions.

\section{Simulation of the $(18 C 6)_{10}$ aggregate at the interface}

As the $18 \mathrm{C} 6$ molecules are neutral and only weakly polar, there were simulated using a standard treatment of electrostatic interactions (i.e. without Ewald). At the beginning of the simulation two stacks of five $\mathrm{D}_{3 \mathrm{~d}}$ molecules of $18 \mathrm{C} 6$ were placed at the interface, equally shared by the two solvents (Fig. 2).

Distribution with respect to the interface. During the dynamics, these stacks completely rearranged. Some of

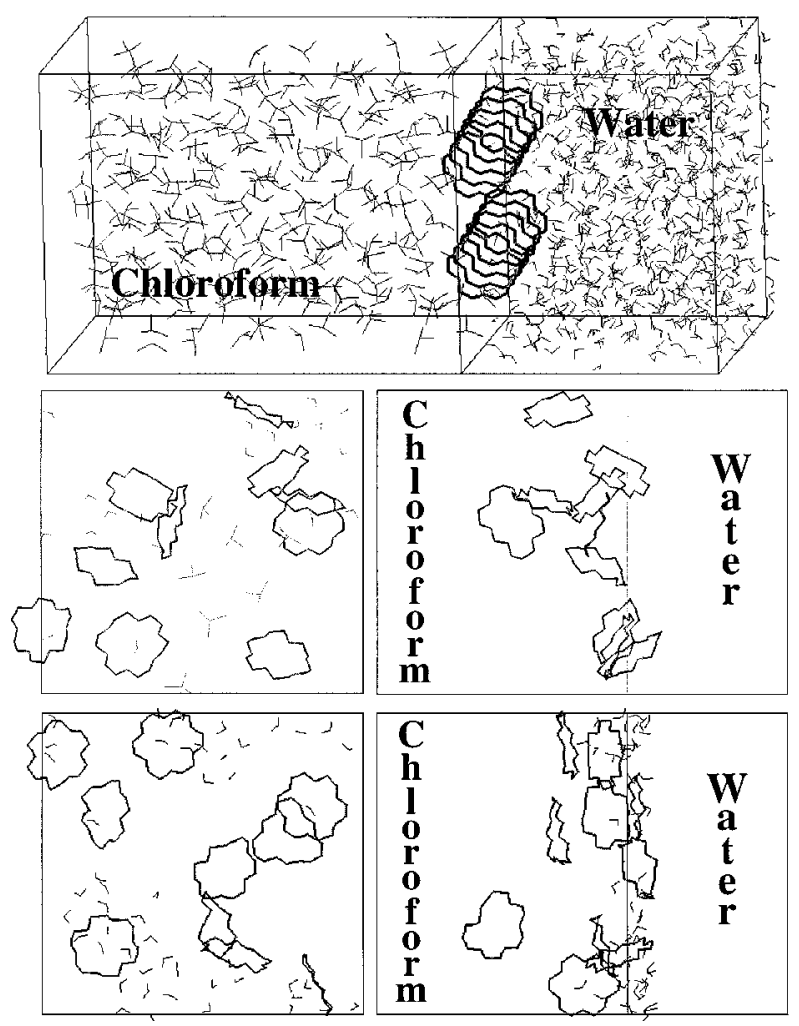

Fig. 2 Simulation of the (18C6) $)_{10}$ aggregate at the interface. Simulation box at $0 \mathrm{ps}$ (top). Snapshot at $500 \mathrm{ps}$ (middle) and $1 \mathrm{~ns}$ (bottom) (orthogonal views with, for clarity, only a few solvent molecules represented). 


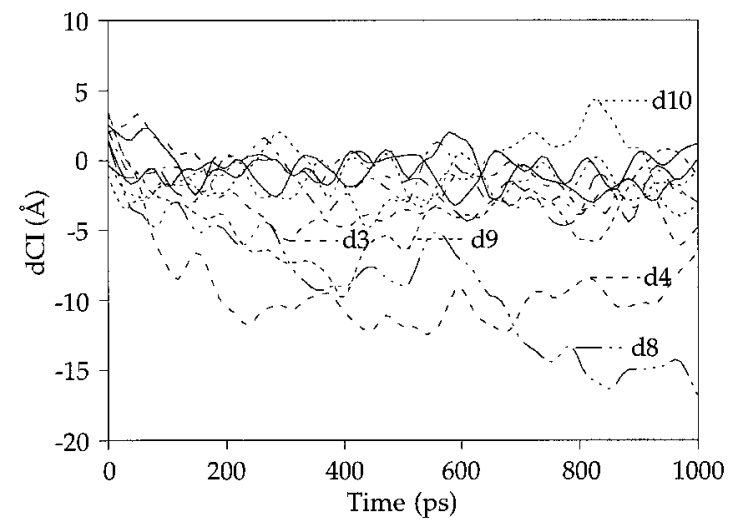

Fig. 3 Simulation of the $(18 \mathrm{C} 6)_{10}$ aggregate at the interface. Distance of the center of mass of each crown ether from the interface, as a function of time.

the molecules adopted different orientations and conformations. To follow their position, we calculated the distance $d_{i}$ between the center of mass of each crown $18 \mathrm{C6}_{i}(i=1$ to 10$)$ and the interface. The time evolution of $d_{\text {i }}$ (Fig. 3) shows that none of the 18C6 molecules diffused to the water phase. Most of them remained at, or close to the interface, with a marked preference for the chloroform side. At about $200 \mathrm{ps,} \mathrm{some} \mathrm{of} \mathrm{them}$ have started to move (by about $5 \AA$ ) in the organic phase. At the end of simulation, one was completely in chloroform $\left(d_{8}\right.$ is about $\left.15 \AA\right)$, and another was at about $10 \AA$. Only one crown (see $d_{10}$ ) was somewhat more on the water side, but still adsorbed at the interface. If one follows individual trajectories, it can be seen that some of the crowns (see e.g. $d_{9}$ and $d_{4}$ ) first moved away from the interface (about $10 \AA$ ), but then returned closer (about $5 \AA$ ). They remained $\mathrm{D}_{3 \mathrm{~d}}$ and coordinated to water molecules. Thus, the fact that most of the molecules stay close to the interface is not an artefact due to the starting situation and from too short simulated times, but very likely corresponds to an equilibrium situation. It also indicates that ionophores are not static at the interface, but in motion.

The energy component analysis between the solute and the solvents (Table 2) shows that, at the end of the simulation, the 18C6 molecules that remained at the interface have equal interactions with water and with chloroform solvents (about $-25 \mathrm{kcal} / \mathrm{mol}$ ), while those which diffused to chloroform interact with chloroform only (by about $-46 \mathrm{kcal} / \mathrm{mol}$, i.e. somewhat less than the total interaction energy with the two solvents at the interface). These numbers indicate that migration to the organic phase is not driven by enhanced solute/solvent interactions. Solvent cohesive "forces" involving entropy effects may play an important role, but cannot be directly assessed from these simulations.

Conformations of 18C6. During the dynamics, some of crown undergo conformational changes from the starting $\mathrm{D}_{3 \mathrm{~d}}$ structure. This happened with those molecules which are in the chloroform phase, remote from the interface, and have no coordination with water.
Table 2 Average interaction energies and their fluctuations $(\mathrm{kcal} / \mathrm{mol})$ between the $\mathrm{X}$ groups of the solute and chloroform $\left(E_{\mathrm{X} \text {-chl }}\right)$ or water $\left(E_{\mathrm{X} \text {-wat }}\right)$

\begin{tabular}{|c|c|c|c|c|}
\hline \multirow[b]{2}{*}{$X$} & \multicolumn{2}{|c|}{$E_{\text {X-wat }}$} & \multicolumn{2}{|c|}{$E_{\text {X-chlor }}$} \\
\hline & $\begin{array}{c}0-50 \mathrm{ps}^{\mathrm{a}} \\
0.9-1.0 \mathrm{~ns}\end{array}$ & $\begin{array}{l}\text { at interf.b } \\
\text { "in bulk" }\end{array}$ & $\begin{array}{c}0-50 \mathrm{ps}^{\mathrm{a}} \\
0.9-1.0 \mathrm{~ns}\end{array}$ & $\begin{array}{l}\text { at interf. } \\
\text { "in bulk" }\end{array}$ \\
\hline \multicolumn{5}{|c|}{$(18 \mathrm{C} 6)_{10}$ No Ewald } \\
\hline $18 \mathrm{C} 6$ & $\begin{array}{l}-21 \pm 2 \\
-21 \pm 1\end{array}$ & $\begin{array}{r}-26 \pm 2(8) \\
-0 \pm 1(2)\end{array}$ & $\begin{array}{l}-18 \pm 4 \\
-29 \pm 1\end{array}$ & $\begin{array}{l}-25 \pm 2(8) \\
-46 \pm 2(2)\end{array}$ \\
\hline \multicolumn{5}{|c|}{$\left(18 \mathrm{C} 6 \cdot \mathrm{K}^{+} \mathrm{Pic}^{-}\right)_{6} \quad$ No Ewald } \\
\hline $18 \mathrm{C} 6$ & $\begin{array}{l}-14 \pm 4 \\
-12 \pm 3\end{array}$ & $\begin{array}{r}-16 \pm 5(5) \\
6 \pm 1(1)\end{array}$ & $\begin{array}{r}-118 \pm 2 \\
-21 \pm 2\end{array}$ & $\begin{array}{l}-18 \pm 2(5) \\
-32 \pm 3(1)\end{array}$ \\
\hline $\mathrm{K}^{+}$ & $\begin{array}{l}-28 \pm 5 \\
-85 \pm 5\end{array}$ & $\begin{array}{c}-47 \pm 9(2) \\
-127 \pm 10(3) \\
-30 \pm 4(1)^{\mathrm{c}}\end{array}$ & $\begin{array}{r}3 \pm 1 \\
-0 \pm 2\end{array}$ & $\begin{array}{r}-0 \pm 2(2) \\
0 \pm 1(3) \\
-3 \pm 4(1)\end{array}$ \\
\hline $\mathrm{Pic}^{-}$ & $\begin{array}{l}-29 \pm 7 \\
-40 \pm 10\end{array}$ & $\begin{array}{c}-46 \pm 11(5) \\
-6 \pm 2(1)\end{array}$ & $\begin{array}{l}-14 \pm 2 \\
-30 \pm 3\end{array}$ & $\begin{array}{l}-23 \pm 2(5) \\
-68 \pm 5(1)\end{array}$ \\
\hline \multicolumn{5}{|c|}{$\left(18 \mathrm{C} 6 \cdot \mathrm{K}^{+} \mathrm{Pic}^{-}\right)_{6} \quad$ Ewald } \\
\hline $18 \mathrm{C} 6$ & $\begin{array}{l}-7 \pm 1 \\
-9 \pm 2\end{array}$ & $\begin{array}{c}-9 \pm 2 \\
-\end{array}$ & $\begin{array}{l}-14 \pm 2 \\
-20 \pm 1\end{array}$ & $\begin{array}{c}-20 \pm 1 \\
-\end{array}$ \\
\hline $\mathrm{K}^{+}$ & $\begin{array}{l}-22 \pm 4 \\
-59 \pm 8\end{array}$ & $\begin{array}{c}-25 \pm 5(4) \\
-128 \pm 21(2)\end{array}$ & $\begin{array}{r}-0 \pm 1 \\
0 \pm 1\end{array}$ & $\begin{array}{l}0 \pm 1 \\
-\end{array}$ \\
\hline $\mathrm{Pic}^{-}$ & $\begin{array}{l}-19 \pm 3 \\
-37 \pm 5\end{array}$ & $\begin{array}{c}-37 \pm 5 \\
-\end{array}$ & $\begin{array}{l}-17 \pm 2 \\
-17 \pm 2\end{array}$ & $\begin{array}{c}-17 \pm 2 \\
-\end{array}$ \\
\hline $6(18 \mathrm{C} 6)_{\mathrm{cl}}$ & ${ }_{1} / 6\left(\mathrm{~K}^{+} \mathrm{Pic}^{-}\right)_{\mathrm{wat}}$ & No Ewald & & \\
\hline $18 \mathrm{C} 6$ & $\begin{array}{r}-1 \pm 0 \\
-12 \pm 2\end{array}$ & $\begin{array}{r}-24 \pm 3(3) \\
0 \pm 0(2)\end{array}$ & $\begin{array}{l}-54 \pm 4 \\
-35 \pm 1\end{array}$ & $\begin{array}{l}-27 \pm 2(3) \\
-42 \pm 2(2)\end{array}$ \\
\hline $\mathrm{K}^{+}$ & $\begin{array}{l}-104 \pm 10 \\
-117 \pm 7\end{array}$ & $-\overline{-}$ & $\begin{array}{l}0.3 \pm 0.3 \\
0.1 \pm 0.3\end{array}$ & - \\
\hline $\mathrm{Pic}^{-}$ & $\begin{array}{l}-80 \pm 10 \\
-82 \pm 6\end{array}$ & $\begin{array}{r}-65 \pm 10(2) \\
-116 \pm 12(4)\end{array}$ & $\begin{array}{l}-3 \pm 2.0 \\
-10 \pm 1\end{array}$ & $\begin{array}{r}-14 \pm 2(2) \\
-0 \pm 1(4)\end{array}$ \\
\hline $6(18 \mathrm{C} 6)_{\mathrm{cl}}$ & $/ 6\left(\mathrm{~K}^{+} \mathrm{Pic}^{-}\right)_{\mathrm{wat}}$ & Ewald & & \\
\hline $18 \mathrm{C} 6$ & $\begin{array}{r}-3 \pm 2 \\
-10 \pm 2\end{array}$ & $\begin{array}{r}-20 \pm 4(3) \\
-0 \pm 1(3)\end{array}$ & $\begin{array}{l}-34 \pm 3 \\
-38 \pm 1\end{array}$ & $\begin{array}{l}-27 \pm 2(3) \\
-48 \pm 2(3)\end{array}$ \\
\hline $\mathrm{K}^{+}$ & $\begin{array}{l}-107 \pm 8 \\
-130 \pm 12\end{array}$ & $\begin{array}{l}-129 \pm 12(4) \\
-134 \pm 10(2)\end{array}$ & $\begin{array}{l}0 \pm 1 \\
0 \pm 1\end{array}$ & $\begin{array}{l}0 \pm 1(4) \\
0 \pm 1(2)\end{array}$ \\
\hline $\mathrm{Pic}^{-}$ & $\begin{array}{l}-55 \pm 6 \\
-73 \pm 6\end{array}$ & $\begin{array}{c}-73 \pm 6 \\
-\end{array}$ & $\begin{array}{r}-7 \pm 3 \\
-16 \pm 2\end{array}$ & $\begin{array}{c}-16 \pm 2 \\
-\end{array}$ \\
\hline
\end{tabular}

a. In this column, averages are performed for all $\mathrm{X}$ species at the beginning ( $0-50 \mathrm{ps}$; first line) and at the end $(900-1000 \mathrm{ps}$; second line) of the simulation.

b. In this column, averages are performed over the $900-1000$ ps for those of the $\mathrm{X}$ species which are adsorbed (within $0.4 \AA$ ) at the interface (first line) and for the others which are "in the bulk" (second line). The corresponding number of molecules is given in parenthesis.

c. Corresponds to the "extracted" $18 \mathrm{C} 6 \cdot \mathrm{K}^{+}$complex (see text and Fig. 4B).

Two of them adopted the $\mathrm{C}_{\mathrm{i}}$ form, which is intrinsically the most stable, and predicted to be more populated than the $\mathrm{D}_{3 \mathrm{~d}}$ one in apolar solution. ${ }^{24}$ The lifetime of these $\mathrm{C}_{\mathrm{i}}$ forms was about 500 and $100 \mathrm{ps}$, respectively. At $1 \mathrm{~ns}$ (see Fig. 2), these crowns displayed dihedral angles which are reminiscent of those of the $\mathrm{D}_{3 \mathrm{~d}}$ and $\mathrm{C}_{\mathrm{i}}$ forms. Based on Monte Carlo ${ }^{27}$ and MD simulations ${ }^{28}$, it was predicted that the $\mathrm{D}_{3 \mathrm{~d}}$ form would be stabilized and the most populated form in bulk water. At the interface, we notice that all molecules which remained in contact with the aqueous phase remained $\mathrm{D}_{3 \mathrm{~d}}$ and sol- 
vated by bridging water molecules on one face, as in bulk water. ${ }^{27}$ Figure 2 shows that in the plane of the interface, water makes hydrogen bond networks, which are all connected to ether oxygens of the $D_{3 \mathrm{~d}}$ solutes. Thus, despite its zero dipole moment, the $D_{3 d}$ form displays some amphiphilic character, and asymmetrical surrounding by solvent at the interface. In the organic phase, it adopts "hydrophobic conformations" like $\mathrm{C}_{\mathrm{i}}{ }^{27}$ different from those in the "source phase" or at the interface.

Simulations of the $\left(18 \mathrm{C6} \cdot \mathrm{K}^{+} \mathrm{Pic}^{-}\right)_{6}$ aggregate and of the $\left(18 \mathrm{C6} \cdot \mathrm{K}^{+} \mathrm{Pic}^{-}\right)_{1}$ and $\left(18 \mathrm{C6} \cdot \mathrm{Sr}^{2+} 2 \mathrm{Pic}^{-}\right)_{1}$ monomers, starting at the interface

In this section, we consider different complexes which were simulated starting at the water-chloroform interface, in the hypothetical situation where they are equally shared by the two solvents.

The $\left(18 \mathrm{C} 6 \cdot \mathrm{K}^{+} \mathrm{Pic}^{-}\right)_{6}$ aggregate ("standard simulation"). We first consider the results obtained on $\left(18 \mathrm{C} 6 \cdot \mathrm{K}^{+} \mathrm{Pic}^{-}\right)_{6}$ with the standard calculations (without Ewald). It can be seen from snapshots of the initial and final structures (Fig. 4) that major events took place during the dynamics. First, half of the inclusion complexes dissociated, and their $\mathrm{K}^{+}$ions moved completely to the aqueous phase, while the corresponding crowns remained at the interface. Two of them were sitting right there, while the third one has moved somewhat to chloroform. Concerning the three $18 \mathrm{C} 6 \cdot \mathrm{K}^{+}$that remained complexed, two of them are also right at the interface, shared by the two solvents as in the starting structure.

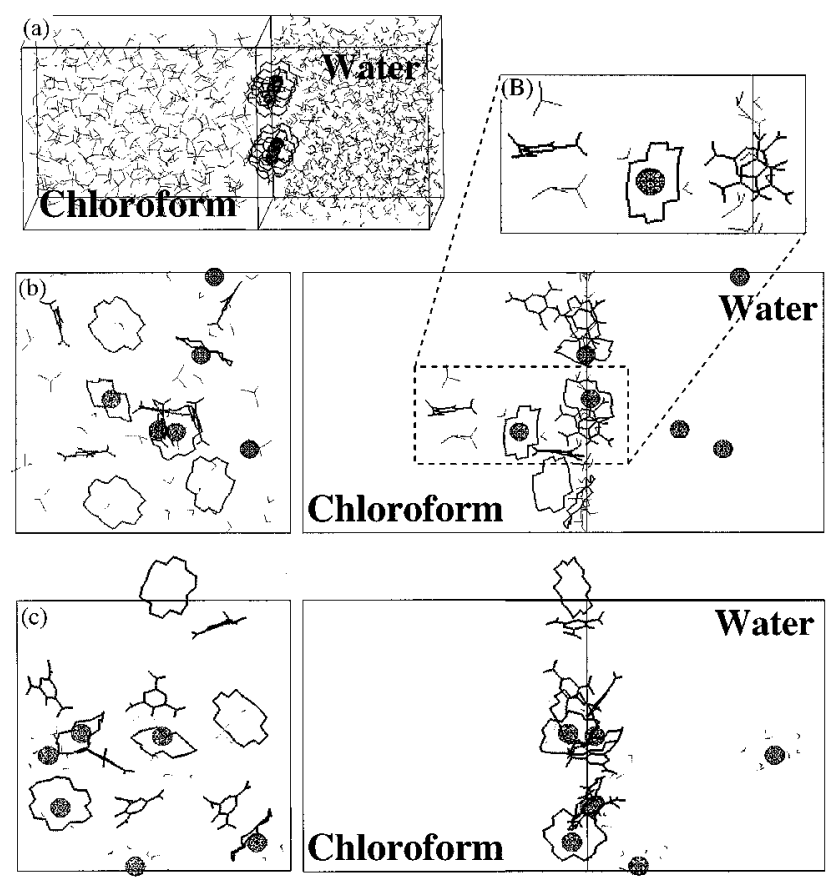

Fig. 4 Simulation of the $\left(18 \mathrm{C} 6 \cdot \mathrm{K}^{+} \mathrm{Pic}^{-}\right)_{6}$ aggregate at the interface. Simulation box at 0 ps (a), snapshots at $1 \mathrm{~ns}$ without Ewald (b), and with Ewald (c) (orthogonal views). Zoom on a $\mathrm{Pic}^{-} \cdots 18 \mathrm{C} 6 \cdots \mathrm{K}^{+} \cdots 2 \mathrm{Pic}^{-}$water separated arrangement (B).
The most spectacular result concerns the migration of one complex into the chloroform phase. Another important feature concerns the $\mathrm{Pic}^{-}$counterions. Despite their negative charge, none of them diffused to water as did the decomplexed $\mathrm{K}^{+}$cations. Four Pic anions remained at the interface, while the two others moved to chloroform. One of them had a very deep position (about $15 \AA$, i.e. more than the deepest $\mathrm{K}^{+}$ complex, or the deepest 18C6 uncomplexed (about $10 \AA$ ).

The curves reported in Fig. 5 display the time evolution distances of different moieties (crowns, anions, cations) of the solute from the interface. Five of the crowns oscillate at a more or less constant distance (about $2 \AA$ ) on the chloroform side of the interface. Sometimes, one of them moves more deeply to chloroform, and comes back. This contrasts with the crown of the $18 \mathrm{C} 6 \cdot \mathrm{K}^{+}$"extracted complex", which moves as deep as $10 \AA$ (at about 700 ps), and finally comes closer to the interface (see $d_{\mathrm{CI} 4}$, Fig. 5). Thus, again, its proximity with the interface at the end of the simulation does not seem to be an artefact due to a too short simulated time, but from a real "affinity" for the interface.

For the counterions, two situations can be distinguished (Figs. 4 and 5). A group of five $\mathrm{Pic}^{-}$sit on the average slightly on the water side of the interface (at about $2 \AA$ ), while the sixth has moved deeply into chloroform (about $10 \AA$ at 400 ps, and $16 \AA$ at 700 ps). Interesting$1 \mathrm{y}$, the latter still interacts with water (about $-6 \mathrm{kcal} /$ mol due to the water dragged molecules), but much less than the five others which remained at the interface $(-46 \mathrm{kcal} / \mathrm{mol})$. All anions display attractive interactions with the chloroform phase $(-23 \mathrm{kcal} / \mathrm{mol}$ for the five at the interface, and $-68 \mathrm{kcal} / \mathrm{mol}$ for the one which is in chloroform).

The $\mathrm{K}^{+}$cations have different positions, depending on their free/complexed states. The complexed $\mathrm{K}^{+}$ which was extracted in chloroform is at about $7 \AA$ (see $d_{\mathrm{KI} 4}$ in Fig. 5), while the two others which are complexed remain right at the interface. The three decomplexed $\mathrm{K}^{+}$ions are, on the average, at about $7 \AA$ in water (see $\left\langle d_{\mathrm{KI}}\right\rangle_{135}$ in Fig. 5). The distances between the $\mathrm{K}^{+}$ions and the center of the corresponding crowns indicates that decomplexation takes place stepwise, and is not reversible. The number of complexes drops from six to five at $220 \mathrm{ps}$, to four at $610 \mathrm{ps}$, and three at 800 ps. We observed that decomplexation takes place when the crown has rotated to become parallel, rather than perpendicular to the interface, i.e. when the environment of the complex is the most asymmetrical. It is thus stressed that such (a)symmetry determines the (in)stability of the complex, and presumably facilitates its formation at the interface.

Another important feature concerns the micro-surrounding of the extracted complex. Its $\mathrm{K}^{+}$ion is coordinated to one $\mathrm{H}_{2} \mathrm{O}$ molecule at each face which brings about $30 \mathrm{kcal} / \mathrm{mol}$ of stabilization (Table 2). Each $\mathrm{H}_{2} \mathrm{O}$ is further hydrogen bonded to a $\mathrm{Pic}^{-}$anion (see Fig. 4). Thus, no counterion is directly coordinated to $\mathrm{K}^{+}$, as it 

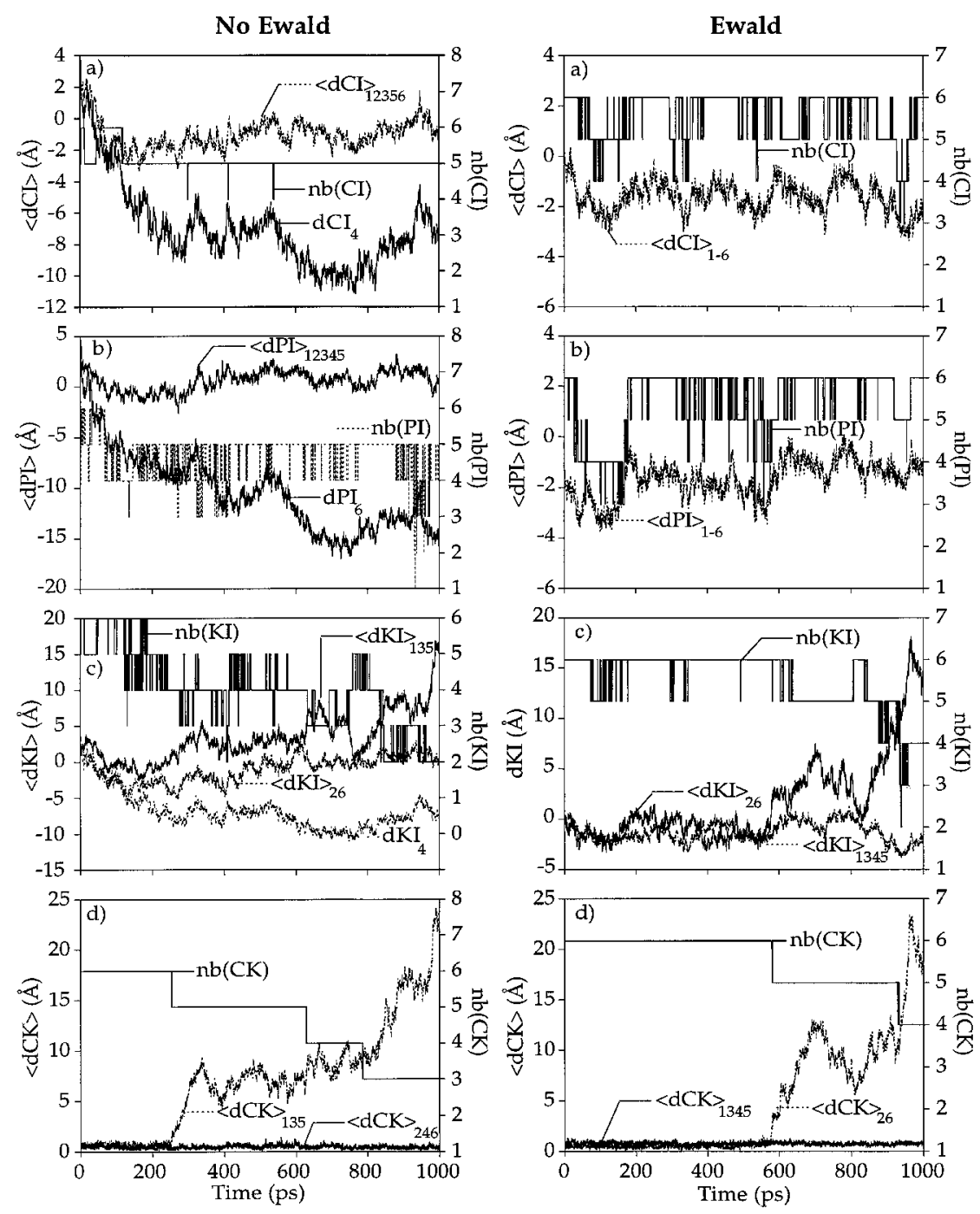

Fig. 5 Simulation of the $\left(18 \mathrm{C} 6 \cdot \mathrm{K}^{+} \mathrm{Pic}^{-}\right)_{6}$ aggregate at the interface. Calculation with Ewald (right) and without Ewald (left). Time evolution of the distances between the interface and the center of mass of groups of crown ethers $\langle\mathrm{dCI}\rangle(\mathrm{a})$, of $\mathrm{Pic}^{-}\langle\mathrm{dPI}\rangle$ (b) and of $\mathrm{K}^{+}<\mathrm{dKI}>$ species (c), and distances between $\mathrm{K}^{+}$and the corresponding crowns $\langle\mathrm{dCK}\rangle$. Negative (/positive) distances correspond to the chloroform (/water) phase. The indices at $\langle\mathrm{d}\rangle$ distances indicate which of the six molecules have been grouped together. $\mathrm{Nb}(\mathrm{CI}), \mathrm{nb}(\mathrm{PI}), \mathrm{nb}(\mathrm{KI})$ correspond to the number of crowns, $\mathrm{Pic}^{-}$and $\mathrm{K}^{+}$, respectively, remaining "at the interface" (within $4 \AA$ ); $\mathrm{nb}(\mathrm{CK})$ is the number of complexed $\mathrm{K}^{+}$cations.

should be in a dry organic phase. Traces of co-extracted water and counterions facilitate the solubilization of the complexed cation in the organic phase where the extracted complex remains of inclusive type. In addition, the 18C6 moiety of this complex displays the largest interactions with chloroform $(-32 \mathrm{kcal} / \mathrm{mol})$.

Concerning the $18 \mathrm{C} 6 \cdot \mathrm{K}^{+}$complexes that remain at the interface, they are clearly more attracted by water than by chloroform (by about -63 and $-18 \mathrm{kcal} / \mathrm{mol}$, respectively), mostly due to the contribution of the encapsulated $\mathrm{K}^{+}$ions.

The $\left(18 \mathrm{C} 6 \cdot \mathrm{K}^{+} \mathrm{Pic}^{-}\right)_{6}$ aggregate ("simulation with Ewald"). The simulations of the same $\left(18 \mathrm{C} 6 \cdot \mathrm{K}^{+}\right.$ $\left.\mathrm{Pic}^{-}\right)_{6}$ system with the Ewald summation leads to results that are consistent with those described above, but with a more pronounced tendency to remain close to the interface. Generally speaking, the solutes tend to be more on the water side of the interface than in the standard simulations. This is illustrated by the final structure obtained after $1 \mathrm{~ns}$ (Fig. 4), and by the time dependent distances from the interface (Fig. 5). Only two of the $18 \mathrm{C} 6 \cdot \mathrm{K}^{+}$complexes decomplexed, and this happened later than in the simulations with Ewald (at about 600 ps) than without Ewald (at about 200 ps). With Ewald, all Pic ${ }^{-}$counterions remained close to the interface, and only two $\mathrm{K}^{+}$cations have moved deeply into water. Another distinct feature is that now, none of the complexes diffuses to the organic phase. 
Examination of the trajectories and of the distances from the interface (Fig. 5) again indicates dynamics processes and oscillatory motions with respect to the interface. For instance, the number of $18 \mathrm{C} 6$ or of Pic anions at the interface is most of the time six, but it may be instantaneously five or four. They undergo oscillation motions rather than deep translations. At the interface, the cations interact with water only $(-25$ $\mathrm{kcal} / \mathrm{mol}$ ), the crowns interact more with chloroform $(-20 \mathrm{kcal} / \mathrm{mol})$ than with water $(-9 \mathrm{kcal} / \mathrm{mol})$, while the reverse holds for the $\mathrm{Pic}^{-}$anions $(-17$ and $-37 \mathrm{kcal} /$ mol, respectively).

The $\left(18 \mathrm{C} 6 \cdot \mathrm{K}^{+} \mathrm{Pic}^{-}\right)_{1}$ monomer (simulation with Ewald). For computer time saving purposes, this complex was simulated with Ewald only. Figures 6 and 7 show that the whole system stayed at the interface and that the complex remained of inclusive type. The $\mathrm{Pic}^{-} \mathrm{K}^{+}$ion pair which was initially intimate dissociated, but $\mathrm{Pic}^{-}$ and $18 \mathrm{C} 6 \cdot \mathrm{K}^{+}$remained at the interface, often on the water side. During the dynamics, $\mathrm{K}^{+}$and $\mathrm{Pic}^{-}$were either separated by a few water molecules, or fully dissociated. The complexed $\mathrm{K}^{+}$cation was coordinated to one to three $\mathrm{H}_{2} \mathrm{O}$ molecules.

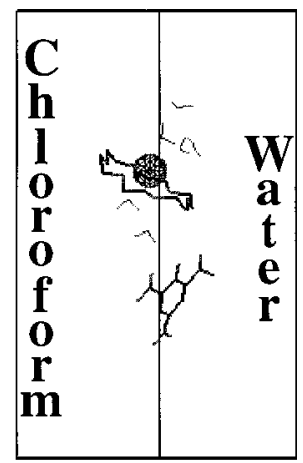

Fig. 6 Simulation (with Ewald) of the $\left(18 \mathrm{C} 6 \cdot \mathrm{K}^{+} \mathrm{Pic}^{-}\right)_{1}$ monomer at the interface. Snapshot at $1 \mathrm{~ns}$.

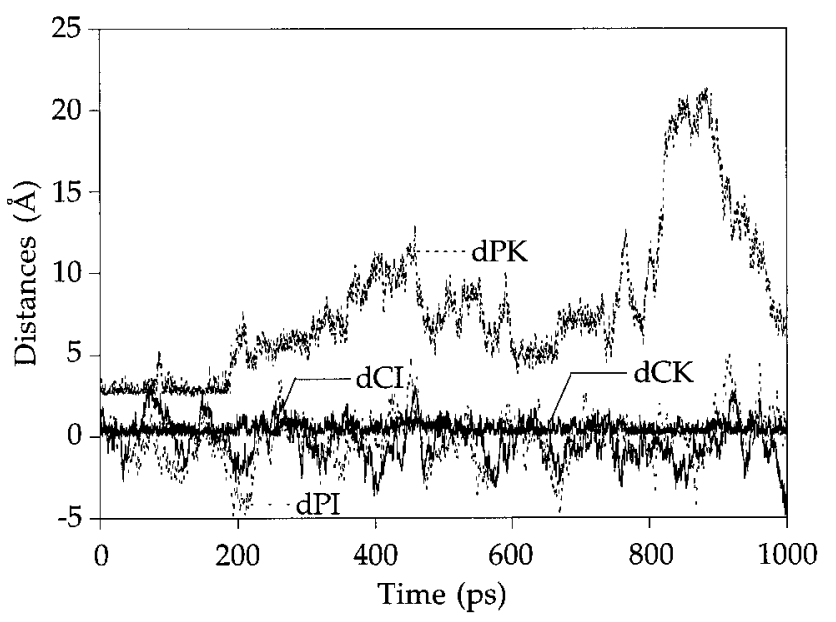

Fig. 7 Simulation of the $\left(18 \mathrm{C} 6 \cdot \mathrm{K}^{+} \mathrm{Pic}^{-}\right)_{1}$ monomer at the interface. Distances from the interface as a function of time. See Fig. 5 for definitions.
Table 3 Average interaction energies and fluctuations (kcal/ mol) between the $\mathrm{X}$ group of the solute and chloroform $\left(E_{\mathrm{X} \text {-chl }}\right)$ or water $\left(E_{\mathrm{X} \text {-wat }}\right)$ at the beginning $(0-50 \mathrm{ps})$ and at the end $(0.9-1.0 \mathrm{~ns})$ of the simulations

\begin{tabular}{cccccc}
\hline & \multicolumn{2}{c}{$E_{\mathrm{X} \text {-wat }}$} & & \multicolumn{2}{c}{$E_{\mathrm{X} \text {-chl }}$} \\
\cline { 2 - 3 } \cline { 5 - 6 } & $0-50 \mathrm{ps}$ & $0.9-1.0 \mathrm{~ns}$ & & $0-50 \mathrm{ps}$ & $0.9-1.0 \mathrm{~ns}$ \\
\hline \multicolumn{2}{c}{$\left(18 \mathrm{C} 6 \cdot \mathrm{K}^{+} \mathrm{Pic}^{-}\right)_{1}$ Ewald } & & & & \\
$18 \mathrm{C} 6$ & $-9 \pm 3$ & $-2 \pm 4$ & & $-17 \pm 3$ & $-15 \pm 3$ \\
$\mathrm{~K}^{+}$ & $-26 \pm 7$ & $-75 \pm 11$ & & $0 \pm 3$ & $-0 \pm 3$ \\
$\mathrm{Pic}^{-}$ & $-25 \pm 7$ & $-63 \pm 11$ & & $-18 \pm 5$ & $-20 \pm 5$ \\
$\left(18 \mathrm{C} 6 \cdot \mathrm{Sr}^{2+} 2 \mathrm{Pic}^{-}\right)_{1} \quad$ Ewald & & & & \\
$18 \mathrm{C} 6$ & $-13 \pm 5$ & $-43 \pm 5$ & & $-6 \pm 2$ & $-10 \pm 3$ \\
$\mathrm{Sr}^{2+}$ & $-81 \pm 21$ & $-539 \pm 105$ & & $-1 \pm 3$ & $0 \pm 0$ \\
$\mathrm{Pic}^{-}{ }_{1}$ & $-23 \pm 8$ & $-54 \pm 25$ & & $-4 \pm 2$ & $-5 \pm 3$ \\
$\mathrm{Pic}^{-}{ }_{2}$ & $-21 \pm 8$ & $-70 \pm 17$ & & $-6 \pm 4$ & $-6 \pm 4$ \\
\hline
\end{tabular}

Why does the $\left(18 \mathrm{C} 6 \cdot \mathrm{K}^{+} \mathrm{Pic}^{-}\right)_{1}$ monomer not migrate to water? Table 3 shows that the whole solute is clearly more attracted by water $(-140 \mathrm{kcal} / \mathrm{mol})$ than by chloroform $(-35 \mathrm{kcal} / \mathrm{mol})$, due to the contributions of $\mathrm{K}^{+}(-75 \mathrm{kcal} / \mathrm{mol})$ and of $\mathrm{Pic}^{-}$ions $(-63 \mathrm{kcal} / \mathrm{mol})$. Based on these numbers only, it could be anticipated that the complex should move to the aqueous phase. Why is it not so? First, let us notice that the 18C6 host is more often perpendicular, rather than parallel to the interface, which enhances the stability of the inclusive form. Second, the latter does not migrate to water because of the solvent cavitation energy. As water has a surface tension much higher than chloroform (72.9 and $26.7 \mathrm{mN} \mathrm{m}^{-1}$, respectively ${ }^{8}$ ) the energy cost for creating a cavity in water is higher than in chloroform, and likely is too large to be compensated by the changes in solute-solvent interactions. On the other hand, while staying at the interface, the solute still enjoys significant stabilizing interactions with the aqueous phase.

Why is the $\left(18 \mathrm{C} 6 \cdot \mathrm{K}^{+} \mathrm{Pic}^{-}\right)_{1}$ complex stable? One may also wonder why this $\left(18 \mathrm{C} 6 \cdot \mathrm{K}^{+} \mathrm{Pic}^{-}\right)_{1}$ complex remained of inclusive type, while some complexes of the $\left(18 \mathrm{C} 6 \cdot \mathrm{K}^{+} \mathrm{Pic}^{-}\right)_{6}$ aggregate dissociated. An interesting feature emerges from the energy component analysis of the two systems, calculated with Ewald for consistency. On the average, the $\mathrm{K}^{+}$cation of the monomer interacts better with water than do the complexed $\mathrm{K}^{+}$cations of the hexamer $(-75$ and $-25 \mathrm{kcal} / \mathrm{mol}$, respectively). This trend results from the fact that, as the concentration of solute species increase at the interface, the local concentration of water decreases. As seen in Fig. 6, the $\mathrm{K}^{+}$ cation of $\left(18 \mathrm{C} 6 \cdot \mathrm{K}^{+} \mathrm{Pic}^{-}\right)_{1}$ is surrounded by 2 to $3 \mathrm{H}_{2} \mathrm{O}$ molecules at each face of the crown, which seems sufficient to prevent decomplexation. Such an arrangement is less probable at a more concentrated (or even saturated) interface, due to the proximity of free crowns or with anions. Another noticeable stabilizing feature of the monomer results from a cooperative solvation effect involving the counterion (see Fig. 6): the phenolate oxygen of $\mathrm{Pic}^{-}$is firmly hydrogen bonded to one water molecule which builds up a relay to $\mathrm{K}^{+}$. In more sophis- 
ticated calculations involving polarization effects, such an arrangement should be further stabilized. Again, this can be hardly achieved in more concentrated conditions. We thus suggest that, for a given ionophore, the inclusive nature of the complexes at the interface depends on their concentration, and markedly on the nature of counterions.

The $\left(18 \mathrm{C} 6 \cdot \mathrm{Sr}^{2+} 2 \mathrm{Pic}^{-}\right)_{1}$ monomer (simulation with Ewald). In order to compare the complexes of monovalent/divalent (and more hydrophilic) ions, we simulated $\left(18 \mathrm{C} 6 \cdot \mathrm{Sr}^{2+} \cdot 2 \mathrm{Pic}^{-}\right)_{1}$ starting with an inclusive $\mathrm{Sr}^{2+}$ ion, in intimate contacts with the two $\mathrm{Pic}^{-}$anions. These simulations were performed with Ewald only. When they started with $18 \mathrm{C} 6 \cdot \mathrm{Sr}^{2+}$ in the plane of the interface and one $\mathrm{Pic}^{-}$in each solution phase, the system rapidly rotated to the position shown in Fig. 8, as a result of the strong adsorption of the anions at the interface. This position is considered as the starting one $(0$ ps). The complex remained bound and at the interface for about $400 \mathrm{ps}$, but then it underwent a slow dissociation. Between 450 and $700 \mathrm{ps}, \mathrm{Sr}^{2+}$ and the anions were separated by a few water molecules (Fig. 8), and $\mathrm{Sr}^{2+}$ was surrounded by water, at about $4 \AA$ from the interface. After $750 \mathrm{ps,} \mathrm{complete} \mathrm{dissociation} \mathrm{took} \mathrm{place:}$

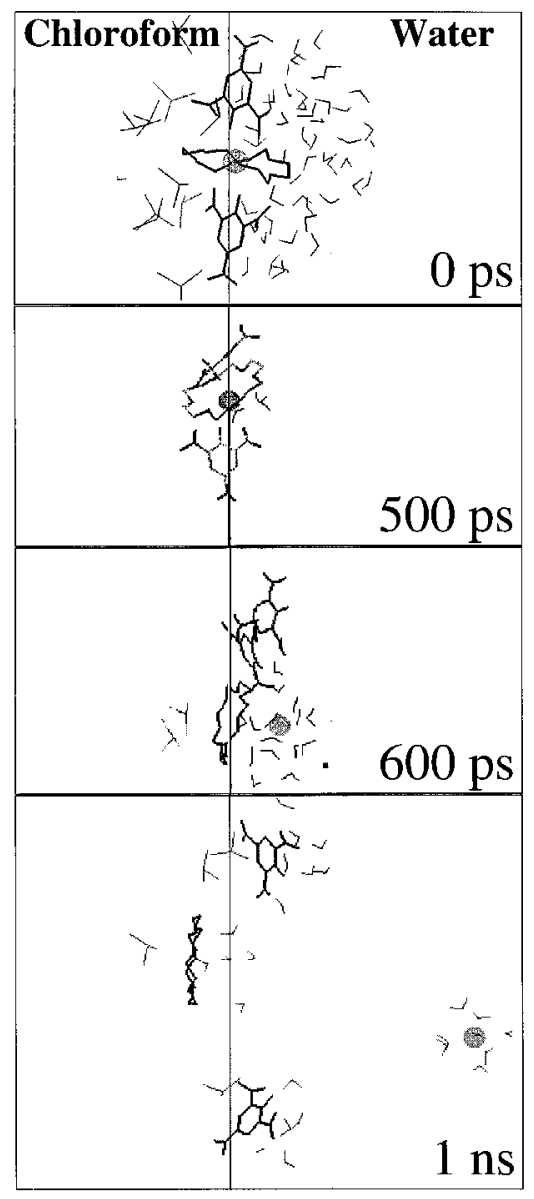

Fig. 8 Simulation (with Ewald) of the $\left(18 \mathrm{C} 6 \cdot \mathrm{Sr}^{2+} 2 \mathrm{Pic}^{-}\right)_{1}$ monomer at the interface. Snapshots (from top to bottom) at 0 ps, $500 \mathrm{ps}, 600 \mathrm{ps}$ and $1 \mathrm{~ns}$.
$\mathrm{Sr}^{2+}$ diffused deeply in water, while the crown and the two $\mathrm{Pic}^{-}$anions remained at the interface (Fig. 9). This behavior, quite different from the one observed with the $\mathrm{K}^{+}$complex, simulated in the same conditions results from the larger hydration energy of $\mathrm{Sr}^{2+}$, compared to $\mathrm{K}^{+}\left(\Delta \Delta G_{\mathrm{hyd}}=259 \mathrm{kcal} / \mathrm{mol}^{44}\right)$. The energy component analysis (Table 3 ) confirms that the decomplexation is mostly driven by the increase of $\mathrm{Sr}^{2+}$ interactions with water (by about $450 \mathrm{kcal} / \mathrm{mol}$ ), and to a minor extent by the increased hydration of $18 \mathrm{C} 6$ and the two Pic anions. The latter always remain at the interface (Fig. 9 ), but slightly more deeply in water than with the $\mathrm{K}^{+}$$\mathrm{Pic}^{-}$complex, presumably because they are attracted by $\mathrm{Sr}^{2+}$.

\section{Simulation of the first stages of the liquid-liquid extraction process, starting with 6(18C6) molecules in chloroform, and $6\left(\mathrm{~K}^{+} \mathrm{Pic}^{-}\right)$ions in water}

The simulations reported above started with the solutes at the interface, to test the response of these hypothetical configurations. In this section, we investigate what happens on the same timescale $(1 \mathrm{~ns})$, when one starts with conditions closer to the experimental ones: initially the salts are in the aqueous phase, while the extractant molecules are in the organic phase, at about $12 \AA$ from the interface. These systems are noted $6(18 \mathrm{C} 6)_{\mathrm{ch} /} / 6\left(\mathrm{~K}^{+} \mathrm{Pic}^{-}\right)_{\text {wat. }}$ As above, we performed two sets of simulations, without and with Ewald, respectively. Figures 10 and 11 show that no ion extraction or complexation by $18 \mathrm{C} 6$ occurred. However, important events have taken place. In both simulations, 18C6 molecules have moved toward the interface, where about three of them adsorbed. The $\mathrm{Pic}^{-}$anions also adsorbed at the interface. In the Ewald calculations, all six $\mathrm{Pic}^{-}$are on the average at about 1 to $2 \AA$ on the water side of the interface. In the no-Ewald calculations, two diffused rapidly and stayed at the interface, while the others stacked by pairs in water, in close contact with $\mathrm{K}^{+}$cations (see Fig. 10). Such anion-anion pairing is fully consistent with the fact that $\mathrm{Pic}^{-}$anions

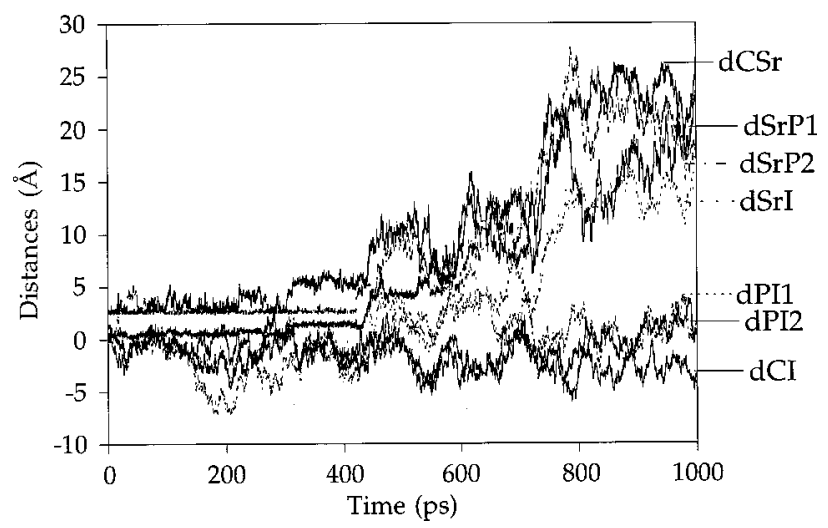

Fig. 9 Simulation of the $\left(18 \mathrm{C} 6 \cdot \mathrm{Sr}^{2+} \cdot 2 \mathrm{Pic}^{-}\right)_{1}$ monomer at the interface. Distances to the interface as a function of time. See Fig. 5 for definitions. 
a)

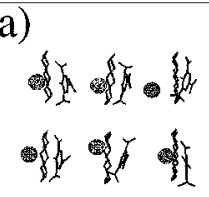

b)

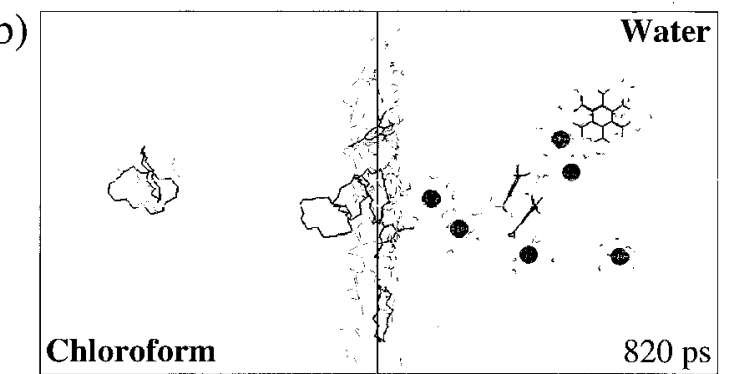

c)

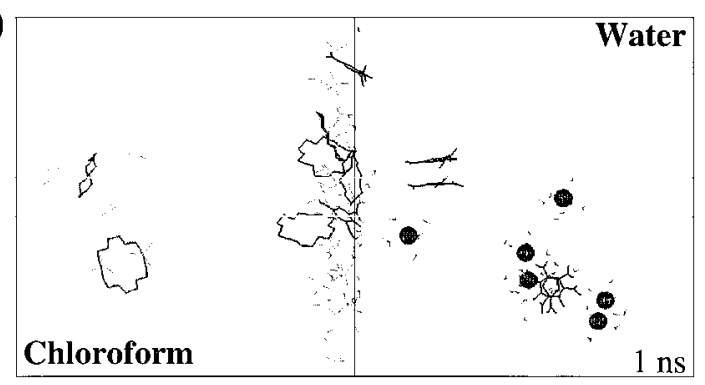

d)

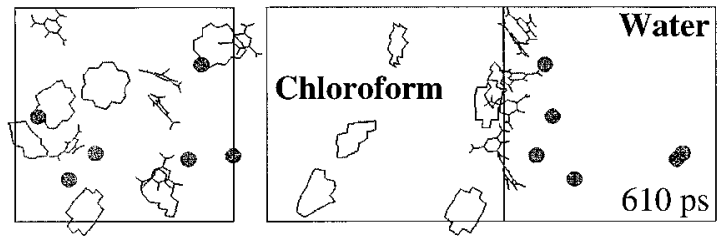

e)
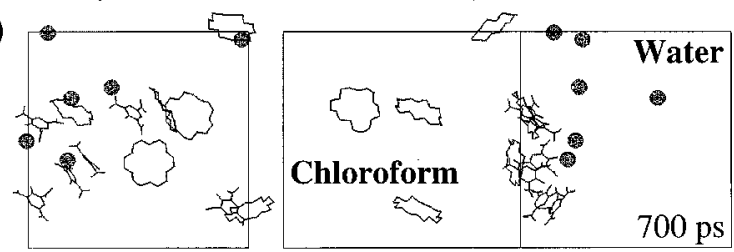

f)
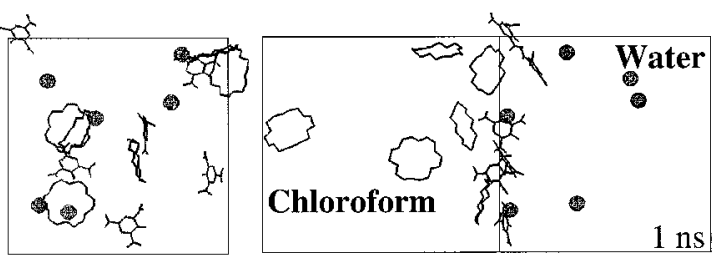

Fig. 10 Simulation of the "extraction process": $6(18 \mathrm{C} 6)_{\mathrm{chl}} /$

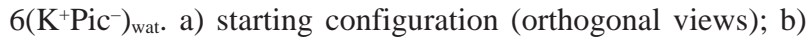
\& c) simulation without Ewald: snapshots at 820 ps and 1 ns. The box has been rotated along the $z$ axis for clarity; d), e) \& f) simulation with Ewald: snapshots at $610 \mathrm{ps}, 700 \mathrm{ps}$ and $1 \mathrm{~ns}$ (orthogonal views).
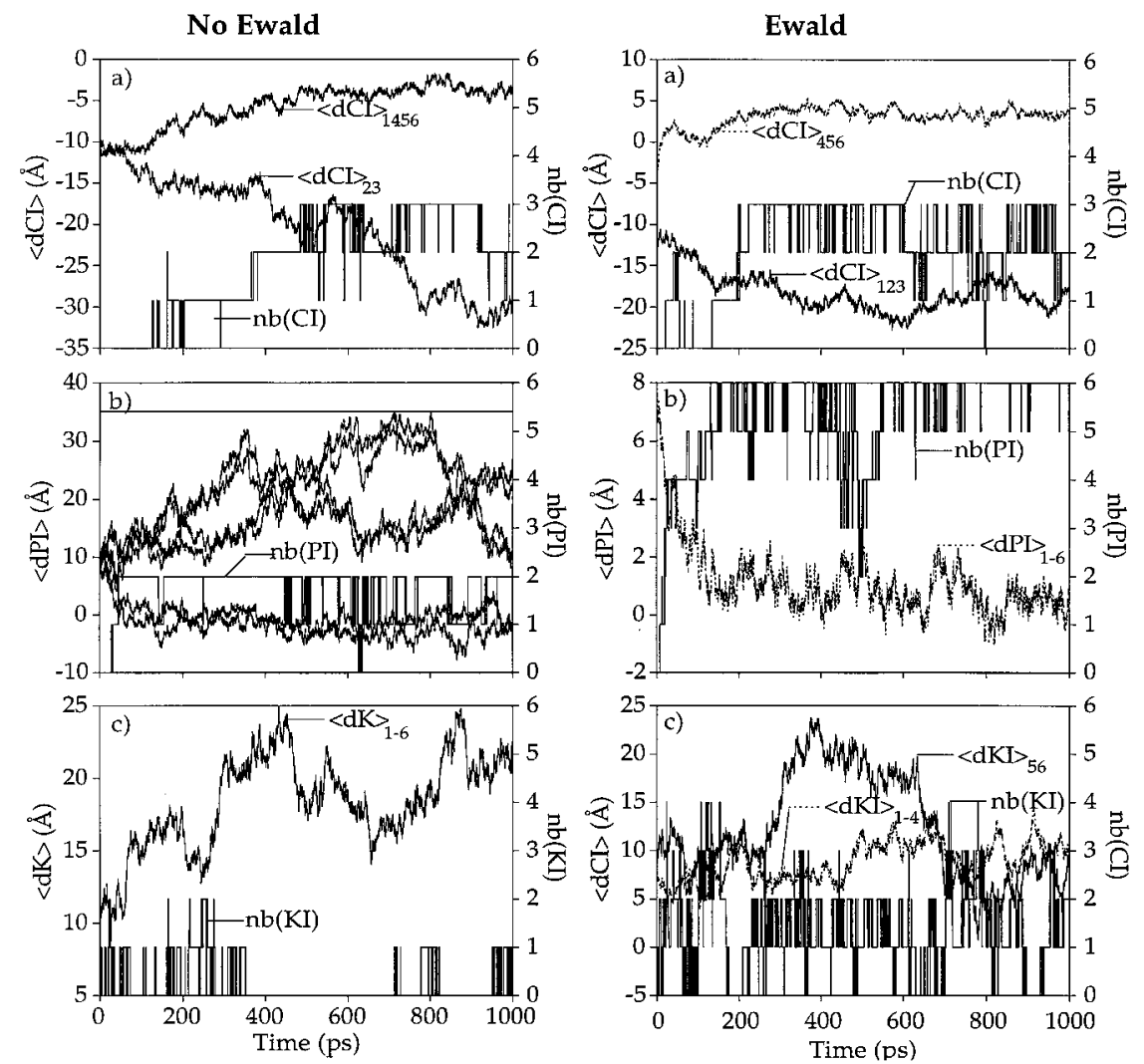

Fig. 11 Simulation of the "extraction process": $6(18 \mathrm{C} 6)_{\mathrm{ch}} / 6\left(\mathrm{~K}^{+} \mathrm{Pic}^{-}\right)_{\text {wat. }}$ Distances from the interface as a function of time. See Fig. 5 for definitions. 
can "attract each other" in water, due to solvation effects. ${ }^{45}$

For the $\mathrm{K}^{+}$cations, distinct behavior can be noticed, in relation with the counterions and the treatment of liquid boundaries. In the no-Ewald calculations, the right side on water (Fig. 10a) corresponds to an air/ water interface". It is remarkable that during these simulations, pairs of $\mathrm{Pic}^{-}$anions close to this interface are accompanied by $\mathrm{K}^{+}$cations. Thus $\mathrm{K}^{+}$cations at more than $20 \AA$ from the water/chloroform interface (see Fig. 11) are indeed close to the water/air interface where they are attracted by $\mathrm{Pic}^{-}$anions. In the Ewald calculation, about 3 to $4 \mathrm{~K}^{+}$remained as expected in the source phase, surrounded by water molecules only. However others moved close to, or at the interface. Thus, although the cations alone would be "repelled" by the interface $e^{46}$, they can be attracted by the surface active Pic counterions.

The energy component analysis at the beginning and at the end of the simulations (Table 2), with Ewald or without Ewald, does not reveal large changes in interaction energies with water nor with chloroform. This suggests that the driving forces for such migrations come mostly from solvent-solvent interactions.

\section{Discussion and Conclusion}

We report the first simulations on a prototypal ionophoric system at an "ITIES": the 18C6 molecule uncomplexed and its $\mathrm{K}^{+} \mathrm{Pic}^{-}$complex. From the methodological point of view, we compared two different protocols concerning the treatment of "long range" electrostatic interactions and the boundaries of the system. Although detailed results are found to depend on the simulation conditions, a number of clear trends emerge from these simulations.

\section{The free ionophores at the interface}

We find that the free 18C6 ionophore displays a high affinity for the interface, rather than for any of the "bulk" phases. This finding is consistent with a number of data, which show that extractant molecules display a high interfacial activity ${ }^{47-49}$, as do neutral acyclic molecules like alcohols or ethers. ${ }^{50}$ Crown ethers like 18C6 and DC18C6 (dicyclohexano-18-crown-6) are surface active and saturate the air/water interface (at concentrations $(\log c)$ of -1.1 and -4.0 , respectively), as do their lipophilic derivatives. ${ }^{51}$ Electrochemical studies show that they assist the cation transfer from water to an organic phase. ${ }^{7,52}$ Interpretation of extraction kinetic data is also consistent with models involving adsorption of crown ethers at the interface..$^{47,53}$ Neutral extractant molecules like TBP form a monolayer at the water/ dodecane interface ${ }^{54}$, a feature which was nicely reproduced by MD simulations..$^{21}$ The enthalpy of adsorption of TBP is comparable to, or somewhat larger than the enthalpy of migration to the organic phase (-10.9 and $-10.3 \mathrm{kcal} / \mathrm{mol}$, respectively). ${ }^{54}$ Similarly, the amphi- philic L-tryptophan molecule adsorbs at the water/ octanol interface and its free energy of adsorption (-5.5 $\mathrm{kcal} / \mathrm{mol})$ is larger than its free energy of transfer $(-1.4$ $\mathrm{kcal} / \mathrm{mol}) .{ }^{55}$ On the computational side, we found that macrocyclic molecules like cryptands, calixarenes, or acyclic ones like CMPO or TBP, adsorb at the interface. ${ }^{17-21,56}$ Our calculations on 18C6 are consistent with these data. However, the picture of the $(18 C 6)_{10}$ aggregate differs from that of (TBP) $)_{10}{ }^{21}$ or of (TPTZ) 16 (Fig. 12) we simulated in comparable conditions. The TBP or TPTZ ionophores form a monolayer with all molecules adsorbed at the interface, while the 18C6 system displays an equilibrium between molecules adsorbed at the interface, and others which have moved somewhat to the organic phase. In our calculations, the interfacial area is about $1100 \AA^{2}$, i.e. ten times the estimated surface of $110 \AA^{2}$ per $D_{3 d}$ crown. At the air/water interface, an average surface of $70 \AA^{2}$ per $18 \mathrm{C} 6$ was calculated from the Gibbs adsorption isotherms ${ }^{51}$, but no value have been reported at a water/chloroform interface. It is not certain whether the absence of monolayer with $18 \mathrm{C} 6$ is due to a too low concentration in the calculations, or corresponds to a real effect. We believe that an increased concentration would induce still more diffusion to the organic phase.

Generally, the orientation of ionophores at the interface favors the ion capture from the aqueous phase (see $\mathrm{TBP}^{21}$, or the 5-Br-PADAP molecule ${ }^{57}$ ). Cyclic ionophores like valinomycin with non equivalent faces adopts at the interface an orientation suitable for ion capture. ${ }^{22 a}$ In the case of a flexible molecule like 18C6,
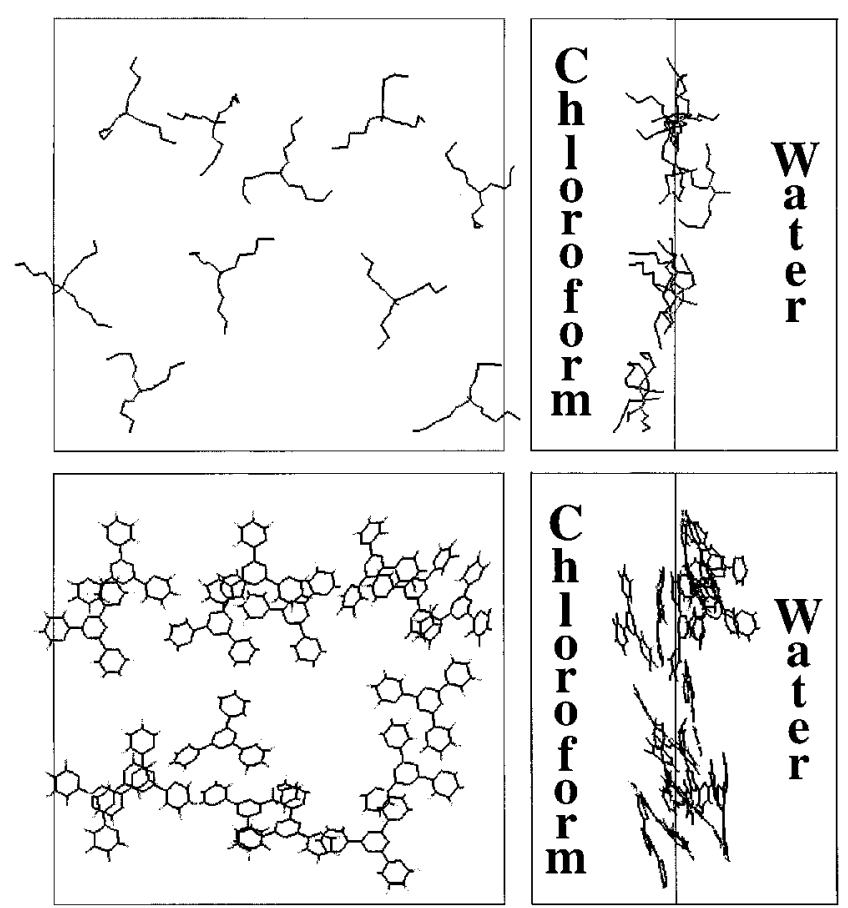

Fig. 12 The (TBP) $)_{10}$ (top) and (TPTZ) 16 (bottom) aggregates after MD simulation at the water/chloroform interface (orthogonal views). 
it is remarkable that the conformation adopted at the interface is the same $\left(\mathrm{D}_{3 \mathrm{~d}}\right)$ as in the $\mathrm{K}^{+}$complex, i.e. for the cation which is selectively bound. This contrasts with the organic phase, where it would be mostly $\mathrm{C}_{\mathrm{i}}$ (without cavity). Thus, adsorption at the interface induces a preorganization of the host for complexation. Similar features should operate for acyclic bidentate extractant molecules like CMPO's, diamides, etc.

\section{The complexes at the interface}

The different simulations on the $18 \mathrm{C} 6 \cdot \mathrm{K}^{+} \mathrm{Pic}^{-}$system lead to different trajectories, depending on the starting conditions, the concentrations, and the protocol used for the simulations. Thus, the timescales of $1 \mathrm{~ns}$ may be too short to provide a statistical representation of the systems at equilibrium. Concerning the simulations with/without Ewald, it is not clear which of the two representations is the less inappropriate. This question remains presently open. However, a number of converging features emerge from these simulations.

First, in diluted conditions (simulations on the $\left(18 \mathrm{C} 6 \cdot \mathrm{K}^{+} \mathrm{Pic}^{-}\right)_{1}$ monomer), the complex adsorbs at the interface and remains of inclusive type. It is more amphiphilic and more surface active than the free crown. This is consistent with the related data on DB18C6 (dibenzo-18-crown-6) in benzene solution, in contact with a $0.017 \mathrm{M} \mathrm{KCl}$ aqueous solution $(\log c$ $=-3.4)^{58}$, as well as with complexes of lipophilic derivatives of crown ethers. Complexes of TBP with salts are more surface active than the free TBP. ${ }^{59}$ Despite their positive charge and repulsive interactions, the 222 $\mathrm{Na}^{+}$cryptates adsorb at the water/mercury interface. ${ }^{60}$ Our MD calculations on cation complexes of calixarenes, cryptands, CMPO, diamides or TBP also revealed similar behavior.

Comparison of the $\left(18 \mathrm{C} 6 \cdot \mathrm{K}^{+} \mathrm{Pic}^{-}\right)_{1}$ and $\left(18 \mathrm{C} 6 \cdot \mathrm{K}^{+}\right.$ $\left.\mathrm{Pic}^{-}\right)_{6}$ simulations starting at the interface provides insights into the effect of concentration. In the more concentrated system, a complex situation is found where the anions are at the interface, some cations are complexed, others are not. In one simulation, a complex has been extracted to chloroform. The simulation of the $6(18 \mathrm{C} 6)_{\mathrm{chl}} / 6\left(\mathrm{~K}^{+} \mathrm{Pic}^{-}\right)_{\text {wat }}$ system ("computer extraction experiment") which started from a completely different situation did not lead to formation of complexes. However, some 18C6 also moved at the interface, as did some $\mathrm{K}^{+}$cations, presumably attracted by the counterions. In some cases, some $\mathrm{K}^{+}$cations are a few Ångströms from 18C6, "ready for complexation" (see Fig. 13).

It is likely that longer MD simulations on this system, or simulations with more concentrated solutes would lead to formation of the complex. The corresponding energy barrier should be lower at the interface than in bulk water solution, because the interface is more "gas phase like", and the energy cost to desolvate the ion is less than in the source phase. Thus, taken together, and based on the fact that the concentration of reactive species is high at the interface, these results suggest
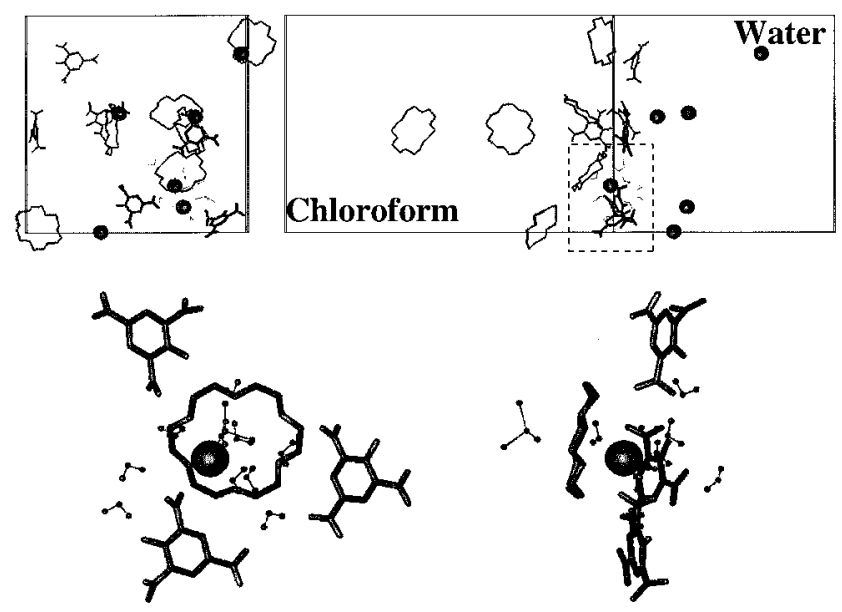

Fig. 13 Simulation (with Ewald) of the "extraction process": $6(18 \mathrm{C} 6)_{\mathrm{chl}} / 6\left(\mathrm{~K}^{+} \mathrm{Pic}^{-}\right)_{\text {wat. }}$. Snapshot at $970 \mathrm{ps}$ of the solvent boxes (top) and of a $18 \mathrm{C} 6 \cdots \mathrm{K}^{+\cdots} \mathrm{Pic}^{-}$moiety "ready for complexation" (orthogonal views).

that complexation takes place at the interface and is facilitated, compared to an homogeneous solution phase. This is fully consistent with current views on related systems. ${ }^{48,53,58,62}$ The interpretation of kinetic data of ion extraction by crown ether derivatives was consistent with an interfacial complexation process. ${ }^{63}$ In a study of $\mathrm{Ni}^{\mathrm{II}}$ extraction by 5 -Br-PADAP at water/ toluene and water/heptane interfaces, Watarai et al. estimated that the percentage of the interfacial reaction over the total reaction rate was respectively $99.9 \%$ and $94.4 \% .{ }^{57}$ The capture and recognition of alkali or guanidinium cations by monolayers of calix[n] arene derivatives at the air/water interface has also been reported. ${ }^{64}$

\section{Anions at the interface facilitate the cation capture and extraction}

The efficiency and selectivity of cation liquid-liquid extraction are markedly influenced by the accompanying counterions $\mathrm{X}^{-}$, mostly due to their dehydration energy. ${ }^{61,65}$ Large and soft polarizable anions like $\mathrm{Pic}^{-}$ are often used in extraction processes because of their "lipophilic character"66 and because they are surface active. ${ }^{49,67}$ It is generally considered that anions are more surface active than cations of similar size. ${ }^{46,68}$ In 1888, Hofmeister established a classification, based on their effects on proteins stability in solution: ${ }^{69}$

$$
\mathrm{SO}_{4}{ }^{2-}=\mathrm{HPO}_{4}{ }^{2-}<\mathrm{F}^{-}<\mathrm{Cl}^{-}<\mathrm{I}^{-}=\mathrm{ClO}_{4}{ }^{-}<\mathrm{SCN}^{-}
$$

These effects are likely related to their interfacial behavior. ${ }^{70}$ It is noticeable that $\mathrm{ClO}_{4}^{-}$, often used as counterion in extraction experiments (see refs. $57 \& 71$ for instance) sits at the right hand side of this series, as should be $\mathrm{Pic}^{-}$. When simulated at the water/chloroform interface, both anions remain adsorbed, while halides migrate to water. ${ }^{72}$ Bulky anions like dicarbollides ${ }^{79}$ should be still more surface active. 
One key question is why cations approach the interface, especially the highly charged and hydrophilic ones. The simulations on the $\left(18 \mathrm{C} 6 \cdot \mathrm{Sr}^{2+} 2 \mathrm{Pic}^{-}\right)_{1} \mathrm{com}-$ plex show that it dissociates after migration to the aqueous phase. In diluted conditions, its concentration at the interface is thus expected to be lower than the concentration of the $\left(18 \mathrm{C} 6 \cdot \mathrm{K}^{+} \mathrm{Pic}^{-}\right)_{1}$ complex. However, the surface activity of anions is felt to markedly determine the lifetime and stability of the complexes at the interface: when suitable anions concentrate of the interface, the local cation's concentration is increased, and complexation may take place. The extraction of actinide or lanthanide cations by TPTZ ligands was found to increase when $\alpha$-halocaproic acid was added to the medium. ${ }^{73}$ This fatty acid, like TBP or TOPO synergists used in lanthanideactinide extraction processes (see ref. 74 and references cited therein) is surface active and facilitates the cation capture at the interface. Synergistic effects in ion extraction ${ }^{75}$ may also be related to interfacial properties, without requiring necessarily co-complexation of the ion.

\section{Computational aspects}

This study demonstrates the power of computer simulations which reproduce known trends on interfacial phenomena, and provide in addition microscopic pictures. They may suffer from a number of limitations: the size of the system may be too small (interfacial area and size of solvent boxes). It is not clear whether the solvents at about $20 \AA$ from the interface are "bulk like", or still perturbed. The representation of the solvents that we used, derived from pure liquid simulations, may not be appropriate for solvent mixtures or interfaces. The dielectric constant of water is likely lower at the interface than in the bulk phase. ${ }^{76}$ The treatment of boundaries and of long range electrostatic interactions are also important. ${ }^{39,77}$ For instance, increasing the cut-off distance enhances the barrier for migration of complexed ionophores from the interface to the organic phase..$^{22,78}$ Non-additivity and polarization effects may also modulate the results obtained by standard pairwise additive potentials. ${ }^{13,16}$ Despite all these limitations, the results presented here and previously are quite encouraging and in overall agreement with related macroscopic data. We hope that they contribute to develop deeper views on solution and interfacial phenomena, and to stimulate further experiments.

The authors are grateful to the CNRS and IDRIS for allocation of computer resources, and to PRACTIS and to EEC (F14W-CT96-0022) for support.

\section{References}

1. C. J. Pedersen, J. Am. Chem. Soc., 89, 7017 (1967).

2. J. M. Lehn, Struct. Bonding, 161, 1 (1973).

3. J. M. Lehn, Angew. Chem., Int. Ed. Engl., 27, 89 (1988); D.
J. Cram, Science [Washington, D. C.], 240, 760 (1988).

4. F. Vögtle, "Supramolecular Chemistry. An Introduction", Wiley, New York, 1991; Y. Inoue and G. Gokel, "Cation Binding by Macrocycles. Complexation of Cationic Species by Crown Ehers", Dekker, New York and Basel, 1990; F. De Jong and D. N. Reinhoudt, "Stability and Reactivity of Crown Ether Complexes", Academic Press, New York, 1981.

5. J.-M. Lehn, "Supramolecular Chemistry. Concepts and Perspectives", VCH, Weinheim, New York, 1995.

6. R. M. Izatt, J. S. Bradshaw, K. Pawlak, R. L. Bruening and B. J. Tarbet, Chem. Rev., 92, 1261 (1992).

7. H. H. Girault and D. J. Schiffrin, in "Electroanalytical Chemistry", ed. A. J. Bard, Vol. 15, pp. 1 - 141, Dekker, New York, 1989; J. Koryta, Ion Selective Electrode Rev., 5, 131 (1983).

8. A. W. Adamson, "Physical Chemistry of Surfaces. 5th ed.", Wiley, New York, 1990.

9. C. M. Starks, C. L. Liotta and M. Halpern, "Phase Transfer Catalysis", Chapmann \& Hall, New York, 1994; W. Lasek and W. Makosza, J. Phys. Org. Chem., 6, 412 (1993); F. Montanari, D. Landini and F. Rolla, Topics Current Chem., 101, 147 (1982).

10. K. B. Eisenthal, Chem. Rev., 96, 1343 (1996).

11. K. Tohda, Y. Umezawa, S. Yoshigawa, S. Hashimoto and M. Kawasaki, Anal. Chem., 67, 570 (1995); Z. Ding, R. G. Wellington, P. F. Brevet and H. H. Girault, J. Phys. Chem., 100, 10658 (1996); H. Watarai and Y. Chida, Anal. Sci., 10, 105 (1994).

12. P. Linse, J. Chem. Phys., 86, 4177 (1987); J. Gao and W. L. Jorgensen, J. Phys. Chem., 92, 5813 (1988); I. Benjamin, J. Chem. Phys., 97, 1432 (1992); A. R. van Buuren, S.-J. Marrink and J. C. Berendsen, J. Phys. Chem., 97, 9206 (1993).

13. T.-M. Chang, K. A. Peterson and L. X. Dang, J. Chem. Phys., 103, 7502 (1995).

14. W. Guba, R. Haessner, G. Breipohl, S. Henke, J. Knolle, V. Sandagada and H. Kessler, J. Am. Chem. Soc., 116, 7532 (1994); W. Guba and H. Kessler, J. Phys. Chem., 98, 23 (1994); A. Pohorille, P. Cieplak and M. A. Wilson, Chem. Phys., 204, 337 (1996); A. Pohorille and M. A. Wilson, J. Chem. Phys., 104, 3760 (1996); C. Chipot, M. A. Wilson and A. Pohorille, J. Phys. Chem. B, 101, 782 (1997).

15. I. Benjamin, J. Chem. Phys., 96, 577 (1992); I. Benjamin, Acc. Chem. Res., 28, 233 (1995); G. M. Torrie and J. P. Valleau, J. Electroanal. Chem., 106, 69 (1986); I. Benjamin, Chem. Rev., 96, 1449 (1996).

16. T.-M. Chang and L. Dang, J. Phys. Chem. B, 101, 10518 (1997).

17. G. Wipff, E. Engler, P. Guilbaud, M. Lauterbach, L. Troxler and A. Varnek, New J. Chem., 20, 403 (1996).

18. M. Lauterbach and G. Wipff, in "Physical Supramolecular Chemistry", ed. L. Echegoyen and A. Kaifer, pp. 65 - 102, Kluwer Academic Publishers, Dordrecht, 1996; G. Wipff and M. Lauterbach, Supramol. Chem., 6, 187 (1995).

19. A. Varnek, L. Troxler and G. Wipff, Chem. Eur. J., 3, 552 (1997).

20. P. Guilbaud and G. Wipff, New J. Chem., 20, 631 (1996).

21. P. Beudaert, V. Lamare, J.-F. Dozol, L. Troxler and G. Wipff, Solvent Extr. Ion Exchange, in press.

22. a) M. Lauterbach, Thesis, Université Louis Pasteur, Strasbourg, 1997. b) M. Lauterbach, E. Engler, N. Muzet, L. Troxler, G. Wipff, J. Phys. Chem. B, 102, 245 (1998).

23. C. J. Pedersen, Fed. Proc. Fed. Am. Soc. Expl. Biol., 27, 1305 (1968). 
24. G. Wipff, P. Weiner and P. A. Kollman, J. Am. Chem. Soc., 104, 3249 (1982).

25. P. K. Weiner, S. J. Profeta, G. Wipff, T. Havel, I. D. Kuntz, R. Langridge and P. A. Kollman, Tetrahedron, 39, 1113 (1983); Y. Sun and P. A. Kollman, J. Comput. Chem., 12, 33 (1992).

26. M. Billeter, A. E. Howard, I. D. Kuntz and P. A. Kollman, J. Am. Chem. Soc., 110, 8385 (1988); B. Jagannadh, A. C. Kunwar, R. P. Thangavelu and E. Osawa, J. Phys. Chem., 100, 14339 (1996)

27. G. Ranghino, S. Romano, J. M. Lehn and G. Wipff, J. Am. Chem. Soc., 107, 7873 (1985).

28. T. P. Straatsma and J. A. McCammon, J. Chem. Phys., 91, 3631 (1989).

29. L. Troxler and G. Wipff, J. Am. Chem. Soc., 116, 1468 (1994).

30. F. T. H. Leuwerink and W. J. Briels, J. Phys. Chem. B, 101, 1024 (1997).

31. Y. L. Ha and A. K. Chakraborty, J. Phys. Chem., 95, 10781 (1991); F. T. H. Leuwerink and W. J. Briels, J. Chem. Phys., 103, 4637 (1995).

32. D. Gehin, P. A.Kollman and G. Wipff, J. Am. Chem. Soc., 111, 3011 (1989); Y. L. Ha and A. K. Chakraborty, J. Phys. Chem., 96, 6410 (1992); B. Hay, J. Am. Chem. Soc., 116, 6316 (1994); F. T. H. Leuwerink, S. Harkema, W. J. Briels and D. Feil, J. Comput. Chem., 14, 899 (1993); Y. Sun and P. A. Kollman, J. Am. Chem. Soc., 117, 3599 (1995); L. X. Dang and P. A. Kollman, J. Am. Chem. Soc., 112, 5716 (1990); L. X. Dang and P. A. Kollman, J. Phys. Chem., 99, 55 (1995); P. D. J. Grootenhuis and P. A. Kollman, J. Am. Chem. Soc., 111, 2152 (1989); Y. L. Ha and A. K. Chakraborty, J. Phys. Chem., 97, 11291 (1993); P. A. Kollman and Y. X. Sun, J. Am. Chem. Soc., 117, 3599 (1995); P. A. Kollman, D. A. Pearlman and P. Cieplak, J. Chem. Phys., 101, 627 (1994); M. H. Mazor, J. A. Mc Cammon and T. P. Lybrand, J. Am. Chem. Soc., 111, 55 (1989); M. H. Mazor, J. A. McCammon and T. P. Lybrand, J. Am. Chem. Soc., 112, 4411 (1990); J. V. van Eerden, S. Harkema and D. Feil, J. Phys. Chem., 92, 5076 (1988); T. J. Marrone, D. S. Hartsough and K. M. Merz Jr, J. Phys. Chem., 98, 1341 (1994); T. Kowall and A. Geiger, J. Phys. Chem., 99, 5240 (1995); L. Dang, J. Am. Chem. Soc., 117, 6954 (1995).

33. E. D. Glendening, D. Feller and M. A. Thompson, J. Am. Chem. Soc., 116, 10657 (1994); M. A. Thompson, E. D. Glendening and D. Feller, J. Am. Chem. Soc., 116, 10465 (1994); D. Feller, J. Phys. Chem., 101, 2723 (1997); D. Feller, M. A. Thompson and R. A. Kendall, J. Phys. Chem. A, 101, 7292 (1997); M. J. Wilson, R. A. Pethrick, D. Pugh and S. Islam, J. Chem. Soc. Faraday Trans., 93, 2097 (1997).

34. D. A. Pearlman, D. A. Case, J. C. Cadwell, W. S. Ross, T. E. Cheatham III, D. M. Ferguson, G. L. Seibel, U. C. Singh, P. K. Weiner and P. A. Kollman, AMBER4.1, San Francisco, University of California, 1995.

35. S. J. Weiner, P. A. Kollman, D. T. Nguyen and D. A. Case, J. Comput. Chem., 7, 230 (1986).

36. G. Wipff and L. Troxler, in "1st European Conference on Computational Chemistry", Nancy, ed. F. Bernardi and J.L. Rivail, Vol. 330, pp. 325 - 336, AIP Press, Woodbury, 1995.

37. W. L. Jorgensen, J. Chandrasekhar and J. D. Madura, J. Chem. Phys., 79, 926 (1983).

38. W. L. Jorgensen, J. M. Briggs and M. L. Contreras, J. Phys. Chem., 94, 1683 (1990).

39. M. P. Allen and D. J. Tildesley, "Computer Simulation of Liquids", Clarendon Press, Oxford, 1987.

40. J. A. Riddick, W. B. Bunger and T. K. Sakano, "Organic Solvents: Physical Properties and Methods of Purification", Wiley, New York, 1986.

41. H. J. C. Berendsen, J. P. M. Postma, W. F. van Gunsteren and A. DiNola, J. Chem. Phys., 81, 3684 (1984).

42. E. Engler and G. Wipff, unpublished.

43. E. Engler and G. Wipff, in "Crystallography of Supramolecular Compounds", ed. G. Tsoucaris, pp. 471 - 476, Kluwer, Dordrecht, 1996.

44. Y. Marcus, "Ion Solvation", Wiley, Chichester, 1985.

45. L. Troxler, G. Wipff and J. Harrowfield, Submitted for publication.

46. J. E. Randles, Discuss. Faraday Soc., 24, 194 (1957).

47. P. R. Danesi, in "Principles and Practices of Solvent Extraction", ed. J. Rydberg, C. Musikas and G. R. Choppin, Chap. 5, pp. 157 - 207, Dekker, New York, 1992.

48. P. R. Danesi, R. Chirizia and C. F. Coleman, in "Critical Reviews in Analytical Chemistry", ed. B. Campbell, Vol 10, p. 1, CRC Press, Boca Raton, 1980.

49. A. N. Popov, in "The Interface Structure and Electrochemical Processes at the Boundary between Two Immiscible Liquids", ed. V. E. Kazarinov, pp. 179 - 205, Springer Verlag, Berline, 1987.

50. Z. Yoshida and S. Kihara, J. Electroanal. Chem., 227, 171 (1987); J. Cross, "Non-Ionic Surfactants. Chemical Analysis", Dekker, New York, 1987.

51. G. F. Vandegrift and W. H. Delphin, J. Inorg. Nucl. Chem., 42, 1359 (1980).

52. P. D. Beattie, A. Delay and H. H. Girault, Electrochim. Acta, 40, 2961 (1995).

53. T. M. Fyles, J. Membr. Sci., 24, 229 (1985). See also ref. 61.

54. N. H. Sagert, W. Lee and M. J. Quinn, Can. J. Chem., 57, 1218 (1979).

55. D. T. Cramb and S. C. Wallace, J. Phys. Chem. B, 101, 2741 (1997).

56. A. Varnek and G. Wipff, J. Comput. Chem., 17, 1520 (1996); A. Varnek and G. Wipff, J. Mol. Struct. (THEOCHEM), 363, 67 (1996); A. Varnek, C. Sirlin and G. Wipff, in "Crystallography of Supramolecular Compounds", ed. G. Tsoucaris, p. 67, Kluwer, Dordrecht, 1995.

57. H. Watarai, M. Gotoh and N. Gotoh, Bull. Chem. Soc. Jpn., 70, 957 (1997)

58. P. R. Danesi, R. Chiarizia, M. Pizzichini and A. Saltelli, $J$ Inorg. Nucl. Chem., 40, 1119 (1978).

59. E. Chifu, Z. Andrei and M. Tomoaia, Anal. Chim. [Rome], 64, 869 (1974); M. Tomoaia, Z. Andrei and E. Chifu, Rev. Roum. Chim., 18, 1547 (1973).

60. M. Carlà, C. M. C. Gambi and P. Baglioni, J. Phys. Chem., 100, 11067 (1996).

61. B. A. Moyer, in "Supramolecular Chemistry. Molecular Recognition: Receptors for Cationic Guests", ed. J. L. Atwood, J. E. D. Davies, D. D. McNicol, F. Vögtle and J.M. Lehn, Vol. 1, p. 325, Pergamon Press, Oxford, 1996.

62. H. Watarai, Tr. Anal. Chem., 12, 313 (1993).

63. T. M. Fyles, J. Chem. Soc., Faraday Trans. 1, 82, 617 (1986).

64. Y. Ishikawa, T. Kunitake, T. Matsuda, T. Otsuka and S. Shinkai, J. Chem. Soc. Chem. Commun., 1989, 736 (1989); L. Dei, A. Casnati, P. Lo Nostro, A. Pochini, R. Ungaro and P. Baglioni, Langmuir, 12, 1589 (1996); P. Lo Nostro, A. Casnati, L. Bossoletti, L. Dei and P. Baglioni, Colloids Surfaces A, 116, 203 (1996); L. Dei, A. Casnati, P. Lo 
Nostro and P. Baglioni, Langmuir, 11, 1268 (1995).

65. R. L. Bruening, R. M. Izatt and J. S. Bradshaw, in "Cation Binding by Macrocycles. Complexation of Cationic Species by Crown Ethers", pp. 111 - 132, Dekker, New York and Basel, 1990; J. D. Lamb, J. J. Christensen, S. R. Izatt, K. Bedke, M. S. Astin and R. M. Izatt, J. Am. Chem. Soc., 102, 3399 (1980); J. D. Lamb, R. M. Izatt and J. J. Christensen, in "Progress in Macrocylic Chemistry", ed. R. Izatt and J. J. Christensen, Vol. 2, p. 42, Wiley, New York, 1981; R. M. Izatt, G. A. Clark, J. S. Bradshaw, J. D. Lamb and J. J. Christensen, Separation Purification Methods, 15, 21 (1986); U. Olsher, M. G. Hankins, Y. D. Kim and R. A. Bartsch, J. Am. Chem. Soc., 115, 3370 (1993); B. A. Moyer and Y. Sun, Principles of Solvent Extraction of Alkali Metal Ion, 13, 295 (1997).

66. K. E. Koenig, G. M. Lein, P. Stuckler, T. Kaneda and D. J. Cram, J. Am. Chem. Soc., 101, 3553 (1979); G. D. Beresford and F. Stoddart, Tetrahedron Lett., 21, 867 (1980); Y. Hasegawa and H. Date, Solvent Extra. Ion Exchange, 6, 431 (1988).

67. D. F. Evans, J. B. Evans, R. Sen and G. G. Warr, J. Phys. Chem., 92, 784 (1988).

68. K. J. Schweighofer and I. Benjamin, J. Phys. Chem., 99, 9974 (1995).

69. F. Hofmeister, Naunyn-Schmiedebergs Archiv für Experimentelle Pathologie und Pharmakologie, 24, 247 (1888).

70. K. D. Collins and M. W. Washabaugh, Quater. Rev. Biophys., 18, 323 (1985).

71. Y. Marcus and A. S. Kertes, "Ion Exchange and Solvent Extraction of Metal Complexes", Wiley Interscience, Chichester, 1969.

72. F. Berny and G. Wipff, unpublished results. F. Berny,
DEA, Université Louis Pasteur, Strasbourg, 1997.

73. C. Musikas, in "Acitinide/Lanthanide Separations", ed. G. R. Choppin, J. D. Navratil and W. W. Schulz, p. 19, World Scientific Press, Singapore, 1985.

74. G. R. Choppin and K. L. Nash, Radiochim. Acta, 70/71, 225 (1995); J. N. Nathur, Solvent Extra. Ion Exchange, 1, 349 (1983)

75. A. M. Rozen, J. Radioanal. Nucl. Chem., Articles, 143, 337 (1990); I. Natatou, M. Burgard, Z. Asfari and J. Vicens, J. Incl. Phenom. Mol. Recogn. Chem., 22, 107 (1995); H. Watarai, K. Sasaki, K. Takahashi and J. Murakami, Talanta, 42, 1691 (1995).

76. V. P. Sokhan and D. J. Tildesley, Faraday Discuss., 104, 193 (1996).

77. P. A. Kollman, C. Chipot, C. Millot and B. Maigret, J. Chem. Phys., 101, 7953 (1994); B. A. Luty, I. G. Tironi and W. F. van Gunsteren, J. Chem. Phys., 103, 3014 (1995); B. A. Luty and W. F. van Gunsteren, J. Phys. Chem., 100, 2581 (1996); P. E. Smith and W. F. van Gunsteren, in "Computer Simulations of Biomolecular Systems", ed. W. F. van Gunsteren, P. K. Weiner and A. J. Wilkinson, Vol. 2, p.182, ESCOM, Leiden, 1993; A. Warshel and S. T. Russell, Quart. Rev. Biophys., 17, 283 (1984); M. Schaefer and M. Karplus, J. Phys. Chem., 100, 1578 (1996).

78. N. Muzet and G. Wipff, unpublished results.

79. B. Y. Galkin et al., in Proceedings, International Solvent Extraction Conference, Moscow, USSR, 19-24 July 1988, pp. 215 - 218; W. Schulz and L. Bray, Sep. Sci. Technol., 22, 191 (1987).

(Received September 13, 1997)

(Accepted December 10, 1997) 